\title{
Boardroom Centrality and Firm Performance
}

\section{Citation}

Larcker, David F., Eric C. So, and Charles C.Y. Wang. "Boardroom Centrality and Firm

Performance." Journal of Accounting \& Economics 55, nos. 2-3 (April-May 2013): 225-250.

\section{Published Version}

http://www.sciencedirect.com/science/article/pii/S0165410113000141

\section{Permanent link}

http://nrs.harvard.edu/urn-3:HUL.InstRepos:28548030

\section{Terms of Use}

This article was downloaded from Harvard University's DASH repository, and is made available under the terms and conditions applicable to Open Access Policy Articles, as set forth at http:// nrs.harvard.edu/urn-3:HUL.InstRepos:dash.current.terms-of-use\#OAP

\section{Share Your Story}

The Harvard community has made this article openly available.

Please share how this access benefits you. Submit a story.

Accessibility 


\title{
Boardroom Centrality and Firm Performance
}

\author{
David F. Larcker* \\ Stanford University \\ Graduate School of Business \\ Rock Center for Corporate Governance
}

Eric C. So

Stanford University

Graduate School of Business

\author{
Charles C. Y. Wang \\ Stanford University \\ Department of Economics
}

Draft: August 17, 2012

\footnotetext{
* Corresponding email address: Larcker David@gsb.stanford.edu. We thank Alex Edmans, Joey Engelberg, Ben Golub, Matt Jackson, Travis Johnson, Ivo Welch, and seminar participants at Stanford University, University of Toronto, and the WFA for their helpful comments.
} 


\title{
Boardroom Centrality and Firm Performance
}

\begin{abstract}
Firms with central or well-connected boards of directors earn superior risk-adjusted stock returns. Initiating a long position in the most central firms and a short position in the least central firms earns an average risk-adjusted return of $4.68 \%$ per year. Firms with central boards also experience higher future growth in return-on-assets (ROA) with analysts failing to fully reflect this information in their earnings forecasts. Return prediction, growth in ROA, and analyst forecast errors are concentrated among firms with high growth opportunities or firms confronting adverse circumstances, consistent with boardroom connections mattering most for firms that stand to benefit most from the information communicated and resources exchanged through the network of board members. Overall, our results suggest that board of director networks provide economic benefits that are not immediately reflected in stock prices.
\end{abstract}

Keywords: board of director networks; analyst forecasts; market efficiency

JEL Classification: G3; G14; L14 


\section{Introduction}

Social and economic networks are a central feature of virtually all economic activities. These networks serve as a conduit for interpersonal and inter-organizational support, influence, and information flow. The links between individuals in these networks are the channels by which information is communicated, resources are exchanged, new relationships are formed, and existing relationships are leveraged. Economists and sociologists have long studied the influence of social networks on labor markets, political outcomes, and information diffusion.

One important network in corporate finance is the boardroom network formed by shared board directorates. While several studies examine the structure of boardroom social networks, why they form, and their theoretical impact on firm performance, relatively few studies provide empirical evidence to assess the net economic impact of these networks on firm performance. In this paper, we directly investigate the empirical relations between a board's well-connectedness and the firm's future performance.

Our empirical investigation is important because, ex-ante, there are no clear predictions on the relation between a firm's performance and its board's well-connectedness. A vast literature in organizational sociology, economics, and finance highlights both potential benefits and costs associated with being well-networked. The potential benefits of having well-connected boards can take several forms. First, directors possess a wealth of information, on industry trends, market conditions, regulatory changes, and other key market data, which can flow across the boardroom network. Well-connected boards may have better access to this information and a comparative advantage in making strategic decisions. Second, boardroom networks allow firms to leverage social relationships and reduce asymmetric information when designing contracts. Both factors may improve the terms of contracts between firms. Third, directors possess important and useful business contacts accessible through the boardroom network, contacts that can be sources of useful business relationships (e.g., clients, suppliers) or sources of other economic benefits and resource exchange (e.g., personal and political favors). Fourth, the boardroom network may be a mechanism of information transmission through which value-improving business innovations can spread. For example, firms may learn about effective corporate governance mechanisms, efficiency enhancing technology, and innovative compensation structures through the boardroom network. Finally, the boardroom network represents a channel of communication or resource exchange between companies and can facilitate collusive competitive behavior and yield economic benefits for a set of closely linked firms. 
The existing literature also highlights several reasons why having a well-connected board may adversely affect firm performance. First, the boardroom network may propagate valuedecreasing management practices. For example, the boardroom network has been found as an important explanation for the spread of options backdating (Bizjak, Lemmon, and Whitby (2009); Armstrong and Larcker (2009)). Second, to the extent that having a well-connected board requires its members to serve on many board seats, directors of well-connected boards may devote limited attention to the monitoring and strategic advising of each company. Therefore, there may be a tradeoff between well-connectedness and monitoring effort or intensity. This is consistent with the idea that the number of board positions a director holds (or busyness) is negatively associated with monitoring efforts and shareholder wealth (Core, Holthausen, and Larcker (1999) and Fich and Shivdasani (2006)). Third, misleading or incorrect information may spread though the board network, resulting in value decreasing strategies and investments. Finally, although collusion can have a positive impact on shareholder value, the resulting regulatory, litigation, and reputation costs can produce net losses of shareholder value.

The collective arguments from the literature on boardroom networks highlight the ex-ante ambiguity regarding the net economic impact of a board's well-connectedness, and this association is therefore an open empirical question. Resolution of this ambiguity is hampered by the fact that most empirical network studies focus on interpersonal relationships between specific agents within an isolated context, such as between a firm and lender in determining credit terms or a manager and a security analyst in determining analyst recommendations (e.g., Engelberg et al. (2012); Cohen et al. (2010)). An innovation of our paper is that we take a macro-level (or "bird's eye") view on the association between boards' well-connectedness and firm performance. As we explain below, we build the corporate network of shared directorates and measure the relative positioning of boards in the network as a means to aggregate the micro foundations established in prior research. We then assess the balance of the potential costs and benefits associated with a board's "centrality" in the networks and establish several important regularities regarding the relation between board centrality and multiple measures of firm performance.

The construct of interest in our study is the "well-connectedness" of boards established by their directors' formal or professional ties. We conceptualize shared directorates between two boards as channels of information or resource exchange, and study a board's well-connectedness through such channels using standard tools of analysis developed by social network theory. A well-connected board is one that is central to the network's aggregate flow of information and resources. 
The concept of well-connectedness is inherently multidimensional. Network theory has developed multiple related but distinct notions of well-connectedness. First, a board may be wellconnected if it possesses relatively many channels of communication or resource exchange, yielding such a board more opportunities or alternatives than otherwise comparable firms (measured by DEGREE centrality). Second, a board may be well-connected if it possesses relatively closer ties to outside boards (i.e., there are fewer steps between boards), making information or resource exchange quicker and more readily available (measured by CLOSENESS centrality). Third, a board may be well-connected if it lies on relatively more paths between pairs of outside boards, making such a company a key broker of information or resource exchange (measured by BETWEENNESS centrality). We consider a fourth and related notion, stemming from a refinement of DEGREE centrality, which recognizes that having more direct connections is more influential when such connections can reach or influence more outside boards. In other words, a board is well-connected when its direct contacts are also well-connected (measured by EIGENVECTOR centrality). ${ }^{1}$

Using a comprehensive sample of 115,411 directors from 2000 to 2007, we build the U.S. corporate boardroom network formed by shared directorates in each year. For each year, we measure each board's well-connectedness in the aggregate boardroom network using the four standard measures from the networks literature described above, as well as a composite score, which we call "N-Score," based on the average of the four standard measures.

Using these five measures of a board's well-connectedness, we find that firms with the bestconnected boards on average earn substantially higher future excess returns compared to firms with the worst-connected boards. The most central firms (i.e., in the highest centrality quintile) outperform the least central firms (i.e., in the lowest centrality quintile) by an average of $4.68 \%$ per year following the portfolio formation; this association holds after controlling for the influence of industry membership, size, book-to-market, and momentum. We also demonstrate that the link between board connectedness and firm performance is robust over time and across industries and is robust to a standard set of governance controls.

We interpret the positive centrality-return relation as evidence that, all else equal, firms on average experience a net benefit from having a relatively well-connected board and that equity prices under-react to this information. Alternatively, this positive relation reflects compensation for

\footnotetext{
1 The concept of well-connectedness is also relational. The extent to which a board can obtain special advantages by leveraging its professional network depends on whether they are better connected than their peers. In other words, the net economic benefits derived from a board's network depend on how other boards are connected to each other. For this reason, a firm only has limited control over its board's well-connectedness.
} 
unobserved risk factors. While we can never fully rule out risk-based explanations, we design a series of tests to assess the relative merits of risk- and mispricing-based explanations.

Our first test is motivated by the idea that boardroom networks provide access to resources such as shared contacts, best management practices, and improved terms of contracts. We hypothesize that the impact of boards' well-connectedness on firm performance is more pronounced among firms that stand to benefit most from such resources. Consistent with this hypothesis, the return difference between best- versus worst-networked firms is stronger among firms with high growth potential (i.e., young firms or those with low book-to-market ratios), and firms confronting adverse circumstances (with low return-on-assets or poor historical stock price performance).

Our second test is motivated by the hypothesis that the relation between board connectedness and future returns reflects a potential market under-reaction to an unexpected shift in a firm's fundamentals. Consistent with such a hypothesis, we document a positive association between the board's well-connectedness and changes in future profitability as measured by returnon-assets (ROA). Specifically, the changes in ROA of best-networked firms are on average two percentage points higher than that of the worst-networked firms in the year following portfolio formation. In addition, the relation between well-connectedness and future ROA improvements persist into the second year following portfolio formation. Consistent with the results of our returnbased tests, we find that improvements in operating profitability associated with board connectedness are more pronounced among firms with high growth potential or firms confronting adverse circumstances.

Our third test uses analyst forecast errors as a proxy for the under-reaction to the performance-relevant information embedded in board connectedness. We find that firms with relatively better-connected boards are more likely to have realized earnings that exceed the consensus forecast, and conversely firms with relatively less-connected boards are more likely to have realized earnings below the consensus forecast. Consistent with our earlier results, this association is particularly pronounced in firms with high growth potential or those confronting adverse circumstances. These results are consistent with analysts and the market failing to fully appreciate the net economic benefits associated with a company's well-connectedness in the boardroom network, particularly for those firms who stand to benefit the most from network resources. 
Collectively, the results of our paper provide evidence that firms, on average, experience a net benefit from being better-connected in the board of director network and that equity prices under-react to this information. However, it is important to acknowledge that this interpretation is subject to several theoretical and measurement concerns. While studies such as DeMarzo, Vayanos and Zwiebel (2003) and Ballester, Calvó-Armengol, and Zenou (2006) provide rigorous motivation for the network measures used in our study (especially the EIGENVECTOR centrality measure), these theoretical results are based on very specific and fairly simple functional forms for network interactions between participants and for agent utilities. It remains an open question whether our standard centrality measures are consistent with agent interactions in more complex, realistic, and general environments.

Our modeling of the connectedness of boards through shared directorates is also based on several important implicit assumptions. One supposition is that the linkages between firms based on shared board members represent the primary channels of social, informational, and resource exchange between the leadership of companies. It is possible that directors' networks extend beyond those associated with "formal" board appointments and are substantively influenced by "informal" social or non-professional connections. While we may not fully capture the breadth of directors' informal social networks, Hwang and Kim (2011) and Westphal et al. (2006) suggest that formal and informal networks are positively correlated and can be strategically complementary. However, from the perspective of documenting potential mispricing, measuring boards' formal network is more important than their informal network, since the former is more readily observable by market participants.

Moreover our network measures make implicit assumptions about the manner in which traffic flows through the corporate boardroom network. For example, BETWEENNESS and CLOSENESS centrality measures focus on shortest paths between network nodes while ignoring other paths. The use of these measures assumes that as information and resources flow through the network, they only follow the shortest possible paths between network nodes. As noted by Borgatti (2005) and Borgatti and Everett (2006), to the extent these assumptions do not capture the true flow of information and resources across boardroom networks, the use of standard centrality measures may not be completely appropriate.

We also acknowledge that there are plausible alternative causal interpretations of our empirical findings of a positive association between board connectedness and future firm performance. One possibility is that our measures of board connectedness are correlated with some 
unobserved or omitted firm characteristic that is associated with future firm performance. For example, if higher quality directors are attracted to and are more likely to accept board positions on better connected boards (Masulis and Mobbs (2012)), our findings of a positive association between board connectedness and future performance may simply reflect endogenous matching between high quality directors and well-connected or prestigious firms. Another possible explanation is that well-connected board members prefer to sit on the boards of well-performing firms, or firms they correctly anticipate will perform well in the future.

We perform several tests to examine whether these alternative explanations are likely to drive our main results and to assess the possibility that a well-connected board leads to future performance. First, we document a significantly positive association between recent changes in board connectedness (from the previous year to the current year) and future abnormal stock returns among our full sample as well as the subset of firms whose board composition remain unchanged from the previous year. These tests mitigate concerns that our results are driven by firm characteristics, such as board prestige, that are relatively static over time and omitted from our tests. Next, to further mitigate concerns of endogenous matching between boards and firms, we continue to document a positive association between changes in board connectedness and firm performance for the subset of firms whose board composition and outside boardroom connections remain unchanged from the previous to the current year, although with attenuated statistical significance due to the substantially smaller sample size. Finally, we examine the determinants of changes in boardroom connectedness and find no evidence that firms' past performance is associated with future changes in board connectedness. It is therefore unlikely that our results are driven by wellconnected directors being attracted to firms that are expected to perform well in the future. The collective evidence from these tests is consistent with boardroom connectedness leading to better future firm performance by providing access to resources and information. However, we acknowledge that we can never fully rule out other causal explanations, but we emphasize that the endogeneity concerns described above do little to explain the paper's central finding that investors appear to misprice the implications of boards' well-connectedness for firms' future performance.

The remainder of the paper is organized as follows. Section 2 reviews related literature and Section 3 describes the data, the construction of the network, and summarizes network characteristics. Section 4 discusses our empirical results and robustness tests. Section 5 examines alternative explanation for our results. Section 6 provides the summary and conclusions from our study. 


\section{Related Literature}

There is an impressive body of existing literature examining the influence of social networks on economic outcomes. This literature covers a wide range of topics including the diffusion and adoption of innovation (Coleman, Katz, and Menzel (1957)), coalition formation (Kapferer (1969)), group problem solving (Bavelas (1950)), elite decision making (Laumann, Marsden, and Galaskiewicz (1977)), information diffusion in labor markets (Granovetter (1974)), and decisions regarding the level of education that an individual pursues and whether or not to undertake criminal activity (Jackson (2007)). The types of networks examined in these papers include social communities, powerful families and political and economic systems (Padgett and Ansell (1993))examine business interests and marriage patterns in Florentine families in the 1400's, and Galaskiewicz (1985) analyzes CEOs and social club networks).

Most related to our work are numerous studies on the network structure produced by members of boards of directors. For example, Levine (1972) documents the existence of interlocked directorates between the boards of major banks and the boards of major industrials. Dooley (1969) observes that an industrial company whose board is occupied by a banker can obtain capital at favorable rates. Much of this prior research documents how particular interlocks are created (Pfeffer and Salancik (1978)), how they are maintained (Palmer, Friedland, and Singh (1986)), the density of the network and the centrality of firms in the network (Davis, Yoo, and Baker (2003)), and the stability of the network through time (Beckman, Haunschild, and Phillips (2004)). However, relatively little work documents the net economic consequences of these board networks on firm performance. $^{2}$

The association between a firm's performance and the extent of its network is ex-ante theoretically ambiguous. There is an abundance of arguments within organizational sociology and economics on why companies with well-connected boards may benefit from their connections. First, the social capital that is captured by boards' well-connectedness in the network may allow firms to improve the terms of contracts between firms (Schoorman, Bazerman, and Atkin (1981)). Second, because directors have important knowledge and contacts, having a well-connected board may provide better access to such useful knowledge, contacts, and resources, which can benefit firms and

\footnotetext{
2 The notable exceptions to this summary statement include work that documents the impact of the social network on firms' decisions to adopt poison pills (Davis (1991)), switch stock exchanges (Rao, Davis and Ward (2000)), make political contributions (Mizruchi (1992)), engage in acquisitions (Haunschild (1993) and (1994), and Beckman and Haunschild (2002)), and strategic choice (Geletkanycz and Hambrick (1997)).
} 
particularly those that operate in uncertain business environments (Mol (2001); Nicholson, Alexander, and Kiel (2004)). Third, having a well-connected board could also allow for more or better means of information exchange, leading to a reduction in the costs of obtaining information and perhaps improving business decisions (Mizruchi (1990); Mol (2001)). Fourth, board connections also represent a mechanism through which value-improving business innovations can spread - in this way, having well-connected boards can add value to a firm (Haunschild and Beckman (1998)). Finally, interlocking boardroom networks may facilitate collusive competitive behavior, which can yield economic benefits. For example, public policy makers have raised concerns that boardroom networks may restrain competition by providing an unfair economic advantage to firms with network connections (Pennings (1980)).

However, there are also many reasons why well-connectedness in the board network can negatively impact a firm. First, board connections can be a mechanism through which valuedestroying business practices can spread. For example, Snyder, Priem, and Levitas (2009) find that the spread of illegal innovations such as backdating of options is spread through the interlocking boardroom network. Second, to the extent that being well-connected in the boardroom network involves having boardroom members that take on many boardroom jobs, a firm may suffer economically from the deteriorating quality in their directors' monitoring or strategic advising in the firm (Fich and Shivdasani (2006); Fich and White (2001); Loderer and Peyer (2002)). Third, it is possible that misleading or incorrect information is spread through the boardroom network. If strategic decisions depend on this information, it may result in a decrease in shareholder value. Finally, although collusion can have a positive impact on shareholder value, the resulting regulatory, litigation, and reputation costs can produce substantial net losses of shareholder value.

Our paper is related to an emerging body of literature in finance demonstrating the role of personal and social connections in the spread of information. For example, Cohen, Frazzini, and Malloy (2008) demonstrate that past educational connections facilitate information transmission from managers to security analysts. Similarly, Hong, Kubik, and Stein (2005), Kuhnen (2009), and Cohen, Frazzini, and Malloy (2010) provide a link between mutual fund connections and fund performance, suggesting that networks provide information useful for capital allocation decisions.

Our paper also contributes to the literature providing a link between social networks and favorable economic outcomes. For example, Hwang and Kim (2009) and Engelberg, Gao, and Parsons (2012a) demonstrate that socially connected CEO's enjoy higher compensation and retention rates; Faccio, McConnell, and Masulis (2006) establish that politically connected firms have 
a higher likelihood of receiving bailout assistance; and Stuart and Yim (2010) find that connected firms have a higher propensity to be targeted in mergers and acquisitions deals. Our findings corroborate and extend this literature by providing additional evidence of the association between the connectedness of firms' boards and their future performance. Specifically, our results suggest that firms with well-connected boards experience improved operating and stock price performance, particularly among firms most in need of resources and information.

Some prior research has delved into similar empirical questions. For example, Engelberg, Gao, and Parsons (2012b) demonstrate that firms with connections to capital suppliers enjoy more favorable lending terms, improved credit ratings, and superior stock price performance. Boyd (1990) finds that among firms facing a more uncertain business environment, those with more connections to other companies through shared directorates tend to perform better in terms of sales improvements and return on equity. Using a sample of 350 Brazilian firms, Santos, Silveira, and Barros (2009) find that firm value is negatively affected by shared directorates, particularly boards with busy directors and firms in which CEOs hold directorships in other companies. Similarly, Non and Frances (2007) find a negative relationship between the number of shared directorates and future performance for a sample of 101 Dutch firms.

Although these prior studies are important, they are somewhat limited in terms of the sample coverage and choice of measures for their boardroom network. In our study, we calculate board connectedness from a large cross-section of publicly traded and large private firms. Moreover, we consider different dimensions of well-connectedness. Most of the existing papers in this literature focus on a firm's number of boardroom links or the number of outside positions held by the firm's directors. In contrast, we take a broader measurement approach for conceptualizing and empirically measuring the breath of a board's professional network. For example, a firm that does not have many shared board members may still have better access to important resources and information simply by having boardroom connections to few well-connected firms. In the following section we define four different metrics to capture the different dimensions of well-connectedness.

\section{Data and Sample Selection}

\subsection{Construction and Description of Boardroom Network}

Our sample is derived from multiple data sources. We obtain information on companies' board of directors from the Corporate Board Member Magazine Director Database (hereafter referred to as BoardMag) which contains a comprehensive listing of approximately 115,411 directors 
on the boards of all publicly traded companies on the NYSE, NASDAQ, and AMEX, as well as private companies with annual sales exceeding $\$ 1$ billion. This database is updated annually and reflects the most recent information regarding a firm's board of directors as of the publication date. ${ }^{3}$ Using BoardMag data from 2000 to 2007, we construct an undirected and unweighted boardroom network formed by shared directorates. ${ }^{4}$ Shared directorates are defined as follows.

- Two companies are linked if they share at least one board member

- Two companies are not linked if they do not share a board member

As noted in the Introduction, we conceptually model shared directorates between two boards as channels of information or resource exchanges. A well-connected board is therefore one that is central to the boardroom network's aggregate flow of information and resources.

Panel A of Table 1 reports annual summary statistics on the boardroom network we construct. On average we have 6,600 companies and 52,000 directors per year. From 2000 to 2007 we see a $20 \%$ drop in the number of companies in our network, from 7,594 to 6,066. This decline is not attributable to errors arising from data collection or network construction, but is consistent with the $28 \%$ decline in the total number of publicly traded companies on the three major stock exchanges over this period. ${ }^{5}$

We summarize the network structure by comparing the size of the largest and second largest components of the network, where a component is defined as the subset of the network that is totally connected. ${ }^{6}$ On average, $72 \%$ of all companies are connected in a primary central component - this ratio is stable from 2000 to 2007 . In contrast, the second largest components are trivial in size, representing on average $0.001 \%$ of the total number of companies. We also find that

\footnotetext{
${ }^{3}$ An alternative data source is BoardEx data. However, BoardEx has some well-known data problems stemming from the data collection methodology that are not present in the BoardMag data. Specifically, the protocols for BoardEx' data collection, which began in 1999, changed in 2006 and again in 2008. In the beginning, from 1999 to the early 2000s, BoardEx covered roughly only the S\&P1500 companies, their board members and disclosed earners. From 2006 BoardEx began covering senior level directors. In 2008, after the company received additional funding, a dedicated research team was hired to update and add the existing coverage of companies. Though BoardEx has extended its coverage beyond the S\&P1500 over time, it does not backfill data. BoardMag, in contrast has a systematic and welldefined method of collecting data through time; it covers all publicly traded companies and all private companies with sales over $\$ 1$ billion in each year.

4 An undirected network is one in which boardrooms are either connected or not. There is no modeling or assumptions imposed on the direction of the flow of information and resources. An unweighted network is one that does not model or take into account the intensity level of connections between firms.

${ }^{5}$ We computed this number by looking at the total number of unique companies (permco's) each year that are in CRSP with non-missing prices on NYSE, AMEX, and NASDAQ from 2000 2007.

${ }^{6}$ That is, any firm in a component can reach any another node in the component through boardroom connections.
} 
approximately $24 \%$ of the companies in a given year are completely isolated. That is, they do not share any board members with any other firms in our dataset. These firms are typically small publicly traded firms or privately held firms. ${ }^{7}$

To further characterize the structure of the boardroom network, Panel B of Table 1 reports summary statistics on the characteristics of the central component. The average path length of the central component is the average shortest number of steps separating two firms in the component. On average, there is between five to six degrees of separation between any two firms in the central component of our boardroom network, which is consistent with the "six degrees of separation" widely documented in a variety of social networks.

The diameter of the central component is the longest number of steps separating any two firms in the component; in our network we observe an average diameter of 16 . Thus, we observe a "small worlds" phenomenon, as documented in many other social networks (e.g., Milgram (1969)), the phenomenon that large networks, or networks involving a large number of nodes, exhibit small diameters and average path lengths relative to what is expected to result from a randomly formed network.

We also find the clustering coefficient to be on average 0.19 , indicating that $19 \%$ of the time two firms linked with the same firm are also linked with each other. As a benchmark for this measure, we examine the clustering coefficients that would arise from a network formed at random. We simulate 1,000 random networks consisting of the same number of nodes and the same expected number of edges as our boardroom network, and then compute the clustering coefficient for each simulated random network. ${ }^{8}$ These simulations allow us to construct a confidence interval for the clustering coefficient that arises from random networks, and provides a benchmark for our empirically observed clustering coefficients. Table 1 shows that the corporate boardroom network is much more clustered compared to that which would arise from a random network. For example, in 2007 the upper $95^{\text {th }}$ percentile of the simulated clustering coefficient is 0.0014 , which is approximately 121 times less than the actual clustering coefficient of 0.17 . This observation is consistent with the findings from other social networks (e.g., Newman (2003), Grossman (2002), Watts (1999), and Adamic (1999)), suggesting that shared directorates are not formed at random, but may be outcomes of strategic decisions.

\footnotetext{
${ }^{7}$ All of our results are robust when we restrict our analyses to only those firms in the central component, mitigating concerns that our results may be driven by some unique latent factor correlated with the isolated firms.

8 The likelihood of a link between any two nodes is the number of edges divided by the number of nodes.
} 
Finally, Panel C summarizes the distribution of the number of first-degree links to a firm (i.e., DEGREE distribution). On average, a firm in our network is linked with 5 other firms, where the average remains relatively stable over time, ranging from a high of 5.49 in 2007 to a low of 5.22 in 2002. The average degree for a firm in the central component is 6.2, ranging from a low of 5.8 in 2007 to a high of 6.7 in 2002. Figure 1 displays boxplots depicting the annual degree distribution of the boardroom network. Consistent with other observed social networks, our boardroom network exhibits positive skewness in its degree distribution.

In summary, the U.S. boardroom network exhibits many of the same characteristics of other social networks as those observed in prior research. Our boardroom network consists of a primary component accounting for more than $70 \%$ of all firms each year, low average path length between any two nodes, high clustering, and a degree distribution that is heavily right-skewed.

\subsection{Centrality Measures and Firm Characteristics}

As discussed in the Introduction, the concept of well-connectedness is multi-dimensional. We focus on four basic dimensions of well-connectedness that are central to the social networks literature; we describe each dimension conceptually and how they are measured below.

First, a board may be well-connected if it possesses relatively many channels of communication or resource exchange, yielding such a board more opportunities, access, or alternatives than other boards. This concept is measured by DEGREE centrality, which enumerates the number of first-degree links to outside boards. Letting $\delta(i, j)$ denote an indicator that boards $i$ and $j$ share a director, for a given company $i$ in a network,

$$
D E G R E E_{i} \equiv \sum_{j \neq i} \delta(i, j)
$$

Second, a board may be well-connected if it possesses relatively closer ties to outside boards than others, making information or resource exchange quicker and more readily available to such a board. This concept of connectedness is measured by CLOSENESS centrality, which represents how easily or quickly a board can reach an outside board through interlocking directorates. It is defined as the inverse of the average distance between a board and any other board. Letting $l(i, j)$ be the number of steps in the shortest path between board $i$ and board $j$,

$$
\operatorname{CLOSENESS}_{i} \equiv \frac{n-1}{\sum_{j \neq i} l(i, j)}
$$


Third, a board may be well-connected if it lies on relatively more paths between pairs of outside boards, making such a board vital in connecting companies to each other and a key broker of information or resource exchange. This concept is measured by BETWEENNESS (Freeman (1977)), which represents how important a board is in connecting other boards to each other, or how well-situated a board is in terms of the network paths it lies on. BETWEENNESS is defined to be the average proportion of paths between two outside boards on which a board lies. Letting $P_{i}(k, j)$ denote the total number of shortest paths between board $k$ and board $j$, and $P(k, j)$ denote the total number of shortest paths between $k$ and $j$,

$$
\operatorname{BETWEENNESS}_{i} \equiv \sum_{j \neq i: i \notin\{k, j\}} \frac{P_{i}(k, j) / P(k, j)}{(n-1)(n-2) / 2} .
$$

One can interpret the distance of the shortest path between two companies to be proportional to the costs of communication or obtaining favors between them, and as such we can interpret BETWEENNESS as a measure proportional to the average cost of communicating with or obtaining favors from another firm. In other words, a firm may be well-connected because it is relatively less costly for it to obtain resources or favors from outside firms.

Finally, we consider a fourth and related notion of well-connectedness, stemming from Bonacich's (1972) refinement of DEGREE centrality: having more direct connections is more influential when such connection can reach or influence more outside boards. In other words, a board is well-connected when its direct contacts are also well-connected. This concept is measured by EIGENVALUE centrality, which measures a board's well-connectedness based on the wellconnectedness of its direct links:

$$
\lambda \cdot \operatorname{CENTRALITY}_{i} \equiv \sum_{j} g_{i j} \cdot \operatorname{CENTRALITY}_{j}
$$

where $\lambda$ is the proportionality factor and $g_{i j}=1$ if firms $i$ and $j$ are linked. Writing (4) in vector form we see that each firm's well-connectedness in the network can be obtained by the EIGENVECTOR of the matrix $G{ }^{9}$

$$
\lambda \cdot \operatorname{EIGENVECTOR}=G \cdot \operatorname{EIGENVECTOR}
$$

Since the connectedness of a board depends on the connectedness of its direct links, EIGENVECTOR centrality can be interpreted as capturing notions of power and prestige. In other

\footnotetext{
9 The (i,j) element of this matrix, known as the adjacency matrix, is $g_{\mathrm{ij}}$, and equals 1 whenever firms $i$ and $j$ are linked or 0 otherwise.
} 
words, a board may be well-connected when it is perceived to be prestigious and powerful, giving it a special advantage in obtaining resources, information, and favors.

Despite our use of standard network measures, it is important to highlight that our modeling of the boardroom network is based on several implicit assumptions. For example, we assume that the linkages between firms based on shared board members represent the primary channels of social, informational, and resource exchange between the leadership of companies. It is possible that directors' networks extend beyond those associated with "formal" board appointments and are substantively influenced by "informal” social or non-professional connections. While we may not fully capture the breadth of directors' informal social networks, Hwang and Kim (2011) and Westphal et al. (2006) suggest that formal and informal networks are positively correlated and can be strategically complementary. In addition, our network measures above make implicit assumptions about the manner in which traffic flows through the corporate boardroom network. For example, BETWEENNESS and CLOSENESS centrality measures focus on shortest paths between network nodes while ignoring other paths. The use of these measures assumes that as information and resources flow through the network, they only follow the shortest possible paths between network nodes. As noted by Borgatti (2005) and Borgatti and Everett (2006), to the extent these assumptions do not capture the true flow of information and resources across boardroom networks, the use of standard centrality measures may not be completely appropriate.

For each annual volume of the BoardMag data from 2000 to 2007 (available in late May or early June), we construct the entire boardroom network and compute each of the four centrality measures for every firm. We subsequently merge in data on firm characteristics, returns, and analysts' consensus forecasts, obtained from Compustat, CRSP, and IBES, respectively. Firm characteristics are obtained from Compustat using the most recent annual financial statements known prior to the accumulation of returns. We assume a four-month lag between a firm's fiscal year end and the release of the firm's annual financial statements. After merging the board network data with CRSP and Compustat, we eliminate firms with stock prices below \$1. Our final sample consists of 29,637 firm-years spanning 2000 through 2007.

Table 2 contains sample statistics of our final sample. In Panel A of Table 2 we report annual summary statistics of firms' network characteristics as well as their size (defined as the log of market capitalization of common stock outstanding) and book-to-market ratio. Panel B of Table 2 contains firm characteristics by industry, where industries are categorized in terms of their two-digit GICS sector. Financial firms and those from the information technology sector make up the largest 
fraction of our sample. Firms in the materials and utilities industries generally display the highest levels of centrality, suggesting that size and maturity, traits associated with materials and utility firms, are closely linked to our centrality measures. Panel C of Table 2 contains pooled descriptive statistics of the firm characteristics and centrality measures. BETWEENNESS and EIGENVECTOR both display significant skewness, indicating that certain firms play a disproportionate role in linking firms within the boardroom network.

One problematic feature of our centrality measures is that larger firms tend to have larger boards, giving rise to a mechanical positive association between firm size and measures of board connectedness. This is a serious concern because our goal is to develop characterizations of the networks created by shared board directorates rather than imperfect proxies for firm size. To illustrate this issue, we report in Panel A of Table 3 the average annual Pearson (Spearman) correlations between each centrality measure with size (log of market capitalization), ranging from $38.8 \%(55.8 \%)$ to $61.9 \%(61.0 \%)$. As a result of this high correlation with size, the centrality measures are also highly correlated with each other, with a mean average pairwise annual Pearson (Spearman) correlation of $58.9 \%(90.7 \%)$.

To separate the effects of size and board connectedness on firm performance, we create ranked versions of the centrality measures that attempt to purge such measures of their associations with size. Specifically, in June of each year, all firms are ranked into quintiles based on log market capitalization (denoted as SIZE). Within each SIZE quintile, firms are sorted into quintiles based on the four centrality measures: DEGREE, CLOSENESS, BETWEENNESS, and EIGENVECTOR, where highest (lowest) values of centrality assume a value of five (one). The use of quintile ranks reduces the influence of extreme values, adds to the ease of interpretation within the regression results, facilitates portfolio formation in examining cross-sectional return prediction, and provides a non-parametric method to partially control for the impact of firm size on our network measures. ${ }^{10}$ We show in Panel B of Table 3 a correlation table between the size-adjusted centrality measures and size. The average annual Pearson (Spearman) correlations between each size-adjusted centrality measure with size is reduced by a factor of three and now ranges from $8.9 \%(17.7 \%)$ to $20.4 \%$ (20.4\%). Moreover, the average annual Pearson (Spearman) correlation between the size-adjusted

\footnotetext{
${ }^{10}$ As an alternative approach to purging the centrality measures of their association with firm size, we purge the four centrality measures of the effect of size by taking the residual from cross-sectional regressions of DEGREE, CLOSENESS, BETWEENNESS, and EIGENVECTOR on firm size and size-squared. In untabulated results, we confirm our main findings are unchanged when using these alternative size-adjusted centrality measures.
} 
centrality measures is lowered to $52.0 \%(85.7 \%)$. Compared to Panel A, the centrality measures not only have a much lower correlation to size, but also have lower correlations to each other.

It should be emphasized that we use different centrality measures because each measure captures a different notion of a board's well-connectedness. Moreover, it is unclear ex-ante whether one particular concept may be economically more meaningful or relevant than another, and the answer to this question can depend on the structure of the network. ${ }^{11}$ Consistent with prior literature, we find in Table 3 Panels A and B that the four empirical measures of boards' connectedness exhibit a high degree of correlation. That is, those firms with more direct ties to outside boards are also closer to other boards on average and are better positioned to broker communications and resource exchanges between boards. Because the empirical measures of boards' connectedness are highly correlated, our tests of the association between board connectedness and firm performance cannot be treated as being independent. Our multidimensional characterization of well-connectedness is also consistent with prior and related literature in finance (e.g., Hochberg, Ljungqvist, and Lu (2007)) and allows us to examine the sensitivity of our findings to alternative concepts and measurements of the underlying construct of interest.

Table 3 Panel $C$ reports a principal components analysis of the four network measures; the first principal component (the only component with an eigenvalue greater than one) captures nearly $70 \%$ of the variations in the DEGREE, CLOSENESS, BETWEENNESS, and EIGENVECTOR. Since the loadings are approximately the same for each measure, we can interpret the first principal component as an aggregate measure capturing the "overall” well-connectedness of a board. Based on the first principal component, we define a composite network score for each board ("N-Score") by taking the equal-weighted average quintile rank in each of the four aforementioned centrality measures, rounded to the nearest integer and, hence, ranges in value from one to five.

$$
N-\text { Score } \equiv \operatorname{Quint}\left(\frac{1}{4}\left\{\begin{array}{c}
\operatorname{Quint}\left(D_{E G R E E_{i}}\right)+\operatorname{Quint}_{\left(\operatorname{CLOSENESS}_{i}\right)} \\
+Q \operatorname{uint}\left(\text { BETWEENNESS }_{i}\right)+\operatorname{Quint}\left(\text { EIGENVECTOR }_{i}\right)
\end{array}\right\}\right)
$$

Panel D of Table 3 compares the average values of background firm characteristics across quintiles of N-Score. We find that high centrality firms differ from low centrality firms in the following ways. High centrality firms tend to be smaller, younger in age, have higher book-to-market

\footnotetext{
${ }^{11}$ For example, in a star-shaped network the center node is considered the most well-connected, and will rank highly based on DEGREE, BETWEENNESS, or CLOSENESS. In a line network, on the other hand, DEGREE cannot in general distinguish the well-connected from the poorly connected. Instead, notions of well-connectedness captured by BETWEENESS or CLOSENESS better identify the well-networked firms in a line network.
} 
ratio, lower momentum over the trailing 12 months, lower ROA, and smaller total assets. Since these differences in firm characteristics can potentially help explain the differences in future performance between high versus low centrality firms, we include controls for these characteristics in our regression tests. ${ }^{12}$

We adopt a very conservative approach to pair network data with security returns. Specifically, measures of a firm's board centrality are paired with returns that begin to accumulate at the beginning of July of the year following the measurement of the board's centrality. For example, we match a firm's most recent board centrality characteristics as of the BoardMag publication date in 2001 to returns that begin to accumulate in July of 2002 (approximately one year after the board network data is available). This approach ensures that the firm's network characteristics are publicly observable prior to the beginning of the return accumulation period. ${ }^{13,14}$

\section{Empirical Analyses}

\subsection{Return Prediction}

Throughout the analysis, we follow Daniel, Grinblatt, Titman, and Wermers (1997) in calculating characteristic-adjusted returns. In each calendar year, we calculate characteristic-adjusted returns as the difference between a firm's cumulative return and the value-weighted average portfolio of firms matched by size, book-to-market, and momentum, where both returns are measured over identical holding periods. Firms are assigned to characteristic-mimicking portfolios via three nested sorts. Firms are first sorted within size quintiles, second within book-to-market quintiles, and third within momentum quintiles, resulting in 125 mimicking portfolios. Daniel, Grinblatt, Titman, and Wermers (1997) and Chan, Dimmock, and Lakonishok (2009) demonstrate that dependent sorts display lower tracking error variances than independently sorted portfolios and

\footnotetext{
12 As we explain in the next Section, the returns regressions implicitly control for size, book-to-market, and momentum risk characteristics by examining characteristic-adjusted returns.

${ }^{13}$ In establishing a link between centrality and future returns, it is difficult to rule out reverse causality, whereby firms link themselves to high performing firms. We emphasize two aspects of our analysis that help mitigate, but fail to completely eliminate, these concerns. First, we examine the association of centrality with future returns (i.e., they are not measured contemporaneously). Hence, the alternative hypothesis that firms link themselves to high performing firms relies on the idea that firms are able to identify which firms are likely to earn superior security returns in the future. Second, we impose a separation of at least one year between the observation of centrality and the measurement of returns, allowing us to identify board connections that predate the observed returns by a time period exceeding one year. ${ }^{14}$ Eliminating the one-year lag in matching BoardMag data and return accumulation does not materially affect our empirical findings.
} 
that characteristic-adjusted returns produce more statistical power than traditional factor models when evaluating fund managers' ability to produce superior investment returns. ${ }^{15}$

Panel A of Table 4 presents the pooled regression results from regressing one-year-ahead characteristic-adjusted returns on the size-adjusted quintile ranks of the four network measures and $\mathrm{N}$-Score. The t-statistics are reported in parentheses and are based on two-way (firm and year) cluster robust standard errors to account for both cross-sectional and time-series dependence in the residuals (Petersen (2009); Gow, Ormazabal, and Taylor (2010); Thompson (2011)). Two-digit GICS industry and year fixed effects are included throughout. ${ }^{16}$ The regression results demonstrate that all four centrality measures are significantly related to future returns. For example, the coefficient on Quintile(DEGREE) is 0.01 with a t-statistic of 2.83, indicating that the highest quintile of DEGREE outperforms the lowest quintile by approximately 4\% (or (5-1) x $0.01 \times 100$ ) per year, on average, using characteristic-adjusted returns.

Given the robust association between the four standard centrality measures and future returns, it is not surprising that our aggregate centrality measure, N-Score, also demonstrates a statistically significant association with future returns. Panel B reports the pooled average returns to $\mathrm{N}$-Score as well as the average returns to N-Score within each two-digit GICS industry. The pooled results demonstrate that the most central firms earn 3.71\% per year, on a characteristic-adjusted basis, while the least central firms earn $-1.16 \%$. The reported t-statistics corresponding to the portfolio returns are based on Monte Carlo simulations by forming annual empirical reference distributions that randomly assign all firms to quintiles, by matching the observational counts in each N-Score quintile. We simulate 1,000 portfolios for each year and calculate the average long-short difference for each simulated portfolio. We calculate and report average bootstrap t-statistics by contrasting the realized annual hedge returns against the empirical reference distributions. The spread across the high and low N-Score quintiles are most pronounced among firms in the information technology, industrial, and energy sectors, but positive in 7 out of the 10 GICs industries, suggesting that the relation between centrality and firm performance is not limited to a small subset of firms.

\footnotetext{
${ }^{15}$ Lower tracking error indicates that the characteristic-matched portfolio explains a larger fraction of the portfolios performance, resulting in a lower standard error of the estimate of the portfolio's abnormal performance.

${ }^{16}$ In untabulated results, the use of raw, market-adjusted, and size-adjusted returns results in qualitatively similar inferences. Similarly, the use of Fama and French 48 industry fixed effects in place of two-digit GICS does not materially affect the paper's findings.
} 
To examine whether the centrality-return relation documented in Table 4 is persistent across the sample period, Table 5 reports annual breakdowns of the one-year (Panel A) and two-year (Panel B) ahead characteristic-adjusted returns for equal-weighted portfolios formed on N-Score quintiles. The year shown on the left-hand column of Table 5 indicates the vintage of the BoardMag database, where portfolios are formed at the end of June of the subsequent year and returns accumulation begins on the first trading day of July. Panel A shows that the best-connected firms consistently earn higher one-year-ahead characteristic-adjusted returns than the worst-connected firms for all years in our sample, with the exception of 2006, further mitigating concerns that return predictability is driven by a small subset of firm-years. The average difference between high and low N-Score quintile portfolios is $4.68 \%$ with an annual standard deviation of $5.5 \%$, corresponding to an approximated Sharpe ratio of 0.851 . Panel B of Table 5 shows that the best-connected firms earn higher two-year-ahead returns than the worst-connected firms for all years in the sample except 2006. The use of two-year-ahead returns in general increases the magnitude of the return differential as well as the statistical significance, improving the consistency of the association between N-Score and returns.

Having observed the pervasiveness of the centrality-return association across time, we next consider whether this relation is also persistent across different types of firms. Specifically, identifying the characteristics of firms for which this association is particularly strong can provide insights into possible underlying economic mechanisms driving the returns associated with wellconnectedness of boards. The idea that board of director networks provide access to resources such as shared contacts, best management practices, and improved terms of contracts suggests that the impact of board centrality on firm performance should be most pronounced among firms that are most likely to benefit from such resources. Although the boardroom network may benefit many types of firms, we reexamine the relation between board connectedness and firm performance after identifying two subsets of firms that are likely in need of network resources and information. Specifically, we predict that the network effect is more prominent for firms with high growth opportunities, as measured by low book-to-market ratio or young age, and firms confronting adverse circumstances, as measured by low profitability or recent returns. ${ }^{17}$ We expect that any benefits associated with having a well-connected board is likely to be more pronounced in such firms.

\footnotetext{
${ }_{17}$ These subsample analyses are mostly descriptive and need not be the only types of firms among whom boardroom network net benefits are especially strong. There may be other ways of identifying resource-starved firms who are likely to benefit especially from information and resource exchange and we believe these to be interesting questions for future research.
} 
Table 6 reports a partition analysis that estimates regressions of one-year-ahead characteristic-adjusted returns (RET1Y) on N-SCORE for the following subsets of firms: Growth, Young, Low ROA, Low Ret, Growth \& Young, and Low ROA \& Low Ret. Growth, Young, Low ROA, and Low Ret firms are defined to be those firms in the lowest tercile of LBM, AGE, ROA, and MOMEN, respectively, where terciles are formed in the cross-section each calendar year. LBM equals the log of one plus the firm's book-to-market ratio, AGE is the log of the number of prior months that the firm appears in CRSP, ROA is the firm's net income before extraordinary items scaled by beginning-of-year total assets, and MOMEN is the firm's market-adjusted returns over the 12 months following portfolio formation. We interpret lower values of LBM as an indication of expected future growth or higher real options.

Columns (2) through (5) of Table 6 show that the associations between N-Score and future returns are stronger around firms with high growth opportunities, young age, low ROA, and low recent stock price momentum. For each column of Table 6, the 'Coefficient Test' contains p-values from tests of the null hypothesis that the N-Score coefficient is different for the subsample relative to its sample counterpart. For example, the p-value of 0.0141 in Column (2) indicates that the NScore coefficient for the Growth subsample is significantly larger than the N-Score coefficient for the non-Growth subsample. To conduct this test, we run our basic regression specifications on the full sample but fully interact all control variables and fixed effects by the relevant subsample indicator. Across all of the identified subsamples, the coefficient on N-Score is substantially larger among firms with high growth opportunities or those facing adverse circumstances. Moreover, the coefficient on N-Score increases to 0.034 and 0.041 in columns (6) and (7), respectively, when we estimate regression for firms that are both high growth and young and for those that have both low ROA and low returns. These results are consistent with boardroom networks serving as channels of information and resource exchange, and with benefits being more pronounced among those firms who are in greater need of resources.

\subsection{Changes in Profitability}

We next examine whether the centrality-return relation documented above is corroborated by an association between centrality and changes in firms' operating profitability. To parallel the analysis examining security returns, which reflect changes in equity prices, we focus on changes in profitability, rather than the level. Panel A of Table 7 reports the results of a pooled regression of the industry-adjusted year-to-year change in a firm's return on assets, denoted by $\triangle R O A$, on its 
network measures and firm characteristics. We adjust for industry by subtracting off the contemporaneous change in industry median ROA. Specifically, $\triangle \mathrm{ROA}$ is calculated as the one-yearahead changes in ROA (i.e., FY1 ROA minus current ROA) minus the contemporaneous change in industry median ROA. ${ }^{18}$ We regress $\triangle \mathrm{ROA}$ on quintiles of the five centrality measures, as well as lag of $\triangle \mathrm{ROA}(\mathrm{LAG}(\triangle \mathrm{ROA})$ ), MOMEN, LBM, log of total assets (ASSETS), SIZE, AGE, research and development scaled by total sales (RND), long-term debt scaled by total assets (LVG), and log of total sales (SALES). The regression results of Table 7 Panel A demonstrate that firms with wellconnected boards experience a larger increase in future profitability; the coefficient of 0.005 on $\mathrm{N}$ Score indicates that firms in the highest (fifth) quintile experience an increase in ROA that is 2.0\% $((5-1) \times$.005) more than firms in the lowest (first) quintile. Panel B demonstrates that the increase in ROA persists for multiple years following the portfolio formation. Specifically, N-Score is not only associated with increases in FY1 ROA, it is also associated with increases in ROA from FY1 to FY2. This finding corroborates Table 5 results, which demonstrate that N-Score predicts returns in the two years following portfolio formation.

To the extent that the return prediction results reflect a reaction to unexpected increases in profitability, we expect that the association between board centrality and changes in profitability is also stronger among the same types of firms in which the centrality-return associations are stronger. Table 8 demonstrates that the associations between N-Score and industry-adjusted $\triangle \mathrm{ROA}$ are stronger among Growth, Young, and Low Ret firms. We also continue to find a further magnification on the N-Score coefficient for the subset of firms that are both young and high growth. However, we do not find a similar pattern among the subsample of firms with low ROA or those with both low ROA and low momentum.

To summarize, our results demonstrate a positive association between a board's wellconnectedness and its firm's future stock returns, a relation that is robust across time and to alternative measures of well-connectedness. The centrality-return relation is mirrored by a positive relation between board connectedness and innovations in firm profitability. The relation between board connectedness and both measures of future firm performance are more pronounced among

\footnotetext{
18 The use of changes in ROA potentially introduces survivorship bias into our analyses by requiring that a firm be present in the Compustat database in concurrent years. To mitigate this concern, we examine the number of firms that are not included in the Table VII analysis due to missing values of FY1 earnings. The results (untabulated) demonstrate no discernible pattern of sample attrition across quintiles of DEGREE. In total, 1,606 firm-years are eliminated from our analyses due to missing FY1 earnings, with the highest N-Score quintile losing the fewest number of firm-years. An analogous concern applies to the measurement of security returns, which we address by incorporating delisting returns following Shumway (1996).
} 
firms with high growth opportunities and those confronting adverse circumstances. Together, the results are consistent with boardroom connections providing information and resources and the net economic benefits that are not immediately reflected in stock prices.

\subsection{Analyst Forecast Errors}

To explore the possibility that information on the association between board connectedness and firm performance is not fully impounded into prices, we analyze the association between analyst consensus forecast errors and our network measures in Table 9. Under the hypothesis that security prices are slow to incorporate the association between centrality and firm performance, we expect to observe more positive analyst surprises for firms with well-connected boards.

The sample for Table 9 is constructed by merging our base sample with IBES consensus forecasts of FY1 earnings for all firms with at least one analyst providing coverage. The resulting sample consists of 19,264 consensus forecasts spanning 2000-2007. Consensus forecasts are measured at the conclusion of June of each calendar year to best capture the market expectation of FY1 earnings at the date on which we form our centrality portfolios. The dependent variable used in the analysis is the consensus forecast error, defined as the firm's actual FY1 earnings minus the consensus forecast, and scaled by total assets per share. We regress consensus forecast errors on quintiles of our network measures, as well as MOMEN, log of analyst coverage (COV), an indicator variable for firms with low book-to-market ratios (GROWTH), and accruals (ACC). ${ }^{19}$ We also include two additional control variables. First, we include an indicator for firms that experienced a loss in the prior quarter (LOSS). The inclusion of LOSS reflects the fact that analysts tend to overestimate the reversion properties of earnings for loss firms (Brown (2001)). Finally, we include a young firm indicator (YOUNG), as defined above, to account for the fact that there may be greater information uncertainty surrounding the profitability of young firms (Zhang (2006)).

The results in Table 9 Panel A demonstrate that consensus forecast errors are positively and significantly related to each of the five measures of board connectedness, suggesting that analysts are slow to incorporate the economic implications of board centrality when forming expectations of one-year-ahead earnings. Panel B of Table 9 illustrates a similar but economically and statistically

\footnotetext{
${ }^{19}$ Prior research finds that variations in a firm's market value of equity and book-to-market equity ratio explains variations in analyst forecast errors (e.g., Richardson, Teoh, and Wysocki (2004); Guay, Kothari and Shu (2011); So (2012)), and has been used as the two standard controls in studies that analyze analyst forecast errors (e.g., Core, Guay, and Rusticus (2006); Bebchuk, Cohen, and Wang (2012)). Inclusion of LBM or a growth firm indicator does not impact our results. We have implicitly controlled for size through our sorting procedure in the centrality measures.
} 
stronger pattern of associations between our network measures and two-year-ahead (FY2) analyst forecast errors. We again find positive and significant coefficients on the centrality measures, consistent with board centrality being positively and persistently related to the tendency of firms to have realized earnings that exceed the consensus forecast. Moreover, in Panel C of Table 9 we focus on N-Score and examine the associations between boardroom connectedness and one-year-ahead consensus forecast errors among Growth, Young, Low ROA, and Low Ret firms. Consistent with our results in Tables 6 and 8 , we find that the positive associations between board centrality and forecast errors are stronger among firms with high growth opportunities and firms confronting adverse circumstances. Also mirroring the return and $\triangle$ ROA results in Tables 6 and 8 , columns (6) and (7) of Table 9 Panel $C$ shows the coefficient on N-Score is further magnified among the subsample of young growth firms and among the subsample of firms with low ROA and low returns. Together, these findings are consistent with incorrect market expectations regarding the future profitability of well-connected firms.

\subsection{Controlling for Corporate Governance Characteristics}

Boardroom-related empirical measures are often used to measure the strength of a firm's corporate governance, and thus it is important to demonstrate that the association of boardroom connectedness with operating or stock performance is not confounded by firms' corporate governance quality. In this section, we examine whether our results are robust to a standard set of board-related corporate governance control variables measuring the presence of a staggered board, the existence of poison pills and dual class shares, whether the firm has limits to calling special meetings, the percent of independent directors, CEO-Chairman duality, and the shareholder rights governance index (G-Index) of Gompers, Ishii, and Metric (2003).

Consistent with our findings in Tables 6, 8, and 9, Panels A, B, and C of Table 10 show that $\mathrm{N}$-Score continues to be positively associated with future abnormal returns, industry-adjusted changes in future ROA, and consensus forecast errors, after controlling for traditional corporate governance characteristics. Moreover, we continue to find that the association between board centrality and firm performance is particularly strong among those firms that have high growth opportunities or are confronting adverse circumstances. All estimates remain virtually identical in terms of magnitude and statistical significance to those of Table 6, 8, and 9C, suggesting that our primary results are unlikely to be confounded by boardroom-related governance characteristics. 


\section{Alternative Explanations and Additional Analyses}

We acknowledge that there are plausible alternative causal interpretations of the positive association between board connectedness and future firm performance. One explanation is that our measures of board connectedness are correlated with some unobserved or omitted firm characteristic that is associated with future firm performance. For example, board connectedness could be associated with the presence of talented and high quality directors, whose abilities enable their companies to generate abnormal future performance. If higher quality directors are more likely to accept board positions on better connected boards (e.g., Masulis and Mobbs, 2012), our findings of a positive association between board connectedness and future performance may simply reflect the matching between high quality directors and well-connected or prestigious firms. Another related explanation is that well-connected board members prefer to sit on the boards of wellperforming firms or firms they correctly anticipate will perform well in the future. Under this alternative explanation, our findings may simply reflect the preference of well-connected directors for future high performing firms.

We perform a series of tests to explore whether our findings are likely to be driven by these alternative hypotheses, by attempting to identify the associations between exogenous changes in board connectedness to future returns. We begin by estimating the association between recent changes in board connectedness (from the previous year to the current year) and future abnormal

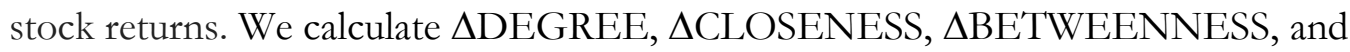

$\triangle$ EIGENVECTOR as a firm's current quintile rank minus its quintile rank in the prior year. $\Delta \mathrm{N}-\mathrm{Score}$ is defined analogously for changes in N-Score. All of the change measures are winsorized at -2 and 2, where higher values correspond to increases in centrality. Panel A of Table 11 demonstrates that future characteristic-adjusted returns are positively associated with changes in board connectedness. We find a positive and statistically significant (at the 1\% level) association between changes in all five measures of board connectedness to one-year-ahead characteristic-adjusted returns.

One issue with the use of changes is that if director quality is positively associated with the size of his network, then our results changes may simply reflect the causal relation between improving director quality and future firm performance discussed above. That is, we would ideally like to study the association between exogenous changes in board centrality and future returns.

Although we do not have a strictly exogenous variable, we can restrict our analysis to the subset of firms whose composition of board members did not change from the prior year to the 
current year. Changes in centrality for such firms must necessarily arise from changes in the boards of other companies in the network or from their board members taking on additional directorships. As a result, changes in centrality for these firms are less likely to result from endogenous choices by the firms in determining or changing their board composition because these changes require decisions by outside companies or changes in boards in other parts of the network.

Panel B of Table 11 contains the results from regressions identical to the changes regression of Panel A except that they are estimated on the sample of firm-years for which the board's membership is identical to the prior year. This restriction causes the sample size to drop from 23,683 to 7,534 firm-year observations. The coefficients on all of the change variables are positive, with the coefficients on $\triangle$ CLOSENESS and $\triangle$ BETWEENNESS being statistically significant at the $10 \%$ level and the coefficient on $\Delta \mathrm{N}$-Score statistically significant at the $1 \%$ level. Together, this evidence is consistent with boardroom connectedness yielding net economic benefits to firms.

An alternative explanation for the results of Table 11 Panels A and B is that well-connected board members join firms that they correctly anticipate will have abnormal positive future performance. We believe that this explanation is unlikely, since this would require outsiders to correctly anticipate firms' one- or two-year-ahead future returns without the market impounding this information into prices. We are not aware of any evidence supporting the notion that managers have this level of foresight about their own firm's future returns, especially those from outside firms. If anything, the recent research by Jenter, Lewellen, and Warner (2011) finds that firm insiders are unable to forecast their own company's stock returns past 100 days. ${ }^{20}$ Another alternative for the results of Table 11 Panels B is that changes in board connectedness, when holding board composition constant, may represent a certification of board quality to which market responds positively over time.

To further explore whether board connectedness leads to future firm performance, we analyze the subset of firms whose board composition as well as their set of outside boardroom connections (i.e., their first-degree network) remain unchanged from the previous to the current

\footnotetext{
${ }^{20}$ In unreported results, we examine the determinants of board connectedness by estimating an ordered logit of changes in our centrality measures on various firm characteristics to firms' performance and growth profiles: LBM, lag of $\triangle R O A$, AGE, MOMEN, ROA, and SIZE. To the extent that firm performance is expected to exhibit autocorrelation, the above hypothesis predicts that recent firm performance may forecast future changes in board connectedness, as well-connected board members seek out seats on future well-performing firms. On the contrary, we do not find a positive association between recent performance and future changes in board connectedness. We do not find any significantly positive coefficients on lag of $\triangle \mathrm{ROA}, \mathrm{MOMEN}$, or ROA. Firms with lower LBM (high growth firms), younger firms, and larger firms tend to experience larger changes in board connectedness. Thus one alternative explanation might be that highly able and well-connected directors prefer to sit on the boards of more glamorous, younger, or larger firms.
} 
year. Changes in boardroom connectedness among these firms must necessarily arise from decisions made in those parts of the network that are more than one degree removed, and thus are more likely to be exogenous. Unfortunately, the remaining set of companies is quite small, as we have only 1,697 total firm-year observations that satisfy these criteria (i.e., 7\% of the total sample of firms in Panel A and $22 \%$ of the sample of firms with unchanged board composition in Panel B), thus there are power concerns for tests based on this much reduced sample.

In Table 11 Panel C, we continue to find that changes in CLOSENESS, BETWEENNESS, EIGENVECTOR, and N-Score are positively associated with one-year-ahead characteristic-adjusted returns. ${ }^{21}$ Since the sample size is small, the associated standard errors increased (by a factor of between three and seven) relative to those of Table 11 Panel B. Nevertheless, the association between changes in BETWEENNESS and one-year-ahead adjusted-returns is significant at the 10\% level. Moreover, the magnitudes of these coefficients remain economically significant across the different measures of board connectedness. Similar to the findings in Panel B, these results suggest that board connectedness yields net economic benefits to firms and casts doubt on the alternative hypotheses explanations of our findings.

In our final analysis, we examine how return predictability associated with the level of centrality varies when conditioning on recent changes to a firm's well-connectedness. In Panel D of Table 11, we sort our sample based on the current year's N-Score and changes in N-Score in the year prior to portfolio formation, and summarize one-year-ahead characteristic-adjusted returns within each bin. To the extent that return predictability originates from investor under-reaction to board centrality, we expect that positive (negative) returns are concentrated among firms who recently ascended (descended) into positions of high (low) centrality. This occurs because we expect investors to gradually learn about the value implications of high centrality over time, perhaps through other channels such as press coverage or firms' disclosures. Consistent with our mispricing interpretation, we find that while firms with high N-Score tend to have higher returns, most of these higher returns are concentrated around firms that experienced an increase in N-Score (i.e., became better-connected). Similarly, while low N-Score firms tend to have lower returns, most of these low returns are concentrated around firms that experienced a decrease in N-Score (i.e., became less wellconnected).

\footnotetext{
${ }^{21}$ Note that there are no results for changes in Degree in this case since, by definition, in this subsample of firms degree remains unchanged between two consecutive years.
} 
Overall, the analyses provided in this section are consistent with security prices underreacting to the implications of firms' well-connectedness for their future performance, particularly among firms with recent improvements in boardroom centrality. While we can never fully rule out alternative causal explanations that are consistent with our set of results, these alternatives do not explain the central finding of this paper that investors appear to misprice the implications of boards' well-connectedness for future firm performance.

\section{Conclusion}

Boardroom networks provide an important conduit of support, influence, and information flow that can affect the economic performance of firms in the network. Prior research on boardroom networks highlights uncertainty regarding the net economic impact of having a wellconnected board, making the association between a board's centrality with the firm's future performance ambiguous ex-ante. Resolution of this ambiguity is hampered by the fact that most empirical network studies focus on interpersonal relationships between specific agents within an isolated context, such as between a firm and lender in determining credit terms or a manager and a security analyst in determining analyst recommendations. An innovation of our paper is that we take a macro-level (or "bird's eye") view on the association between boards' well-connectedness and firm performance. In particular, we analyze the corporate network of shared directorates as a means to aggregate the micro foundations established in prior research.

In this paper, we examine whether differences in boards' well-connectedness explain variations in future firm operating and stock price performance. We find that boards with relatively better-connected boards earn significantly higher future returns than those with less-connected boards. This association holds after controlling for the influence of industry membership, size, book-to-market, and momentum. The centrality-return association is more pronounced in firms that are young, or have high growth opportunities, or low ROA, or low stock momentum, suggesting that board networks may matter most for firms with large future growth opportunities or firms confronting adverse circumstances. We also find that changes in board centrality are significantly associated with future returns, when the composition of a firm's board and even when their firstdegree network remains unchanged.

We also find that firms with better-connected boards experience significantly higher gains in profitability compared to those with less-connected boards, as well as a statistically significant 
relation between board connectedness and the extent to which the firm's realized earnings exceed the consensus analyst forecast. The combination of these results suggests that the analysts fail to incorporate the economic implications of boardroom networks into their forecasts in a timely fashion. To the extent that the consensus analyst forecast is a proxy for market expectations, the positive relation between board centrality and future stock returns appears to stem from expectation errors of firm operating profitability. These results extend the emerging corporate finance literature that highlights the role of networks for setting executive compensation, conveying private information to analysts, and influencing firms' access to capital. Network effects appear to be important not only in specific settings or decisions, but they have a more general impact on the economic performance of firms, particularly resource-needy firms.

While our overall evidence is consistent with board connectedness leading to better firm performance, we acknowledge that these results do not allow us to fully establish a causal relation. Our tests provide descriptive evidence on the balance of costs and benefits associated with board of director networks and establish several important regularities regarding the relation between board centrality and multiple measures of firm performance.

Similarly, our findings do not imply that all firms should or can increase their boardroom centrality in order to increase their future profitability. Although there appears to be substantial economic benefits for at least a subset of firms to improve the breath of their boards' networks, there are many factors that can prevent firms from improving their position in this network. First, a firm must establish either more or higher quality board links with other firms. However, this is a multilateral process that is constrained by frictions such as limits to the number of board positions for a director, formal or informal contractual limitations that prevent board members from sitting on the boards of competitors or important suppliers and customers, limits on the size of a company's board, difficulty forcing existing directors to resign, and costs of finding and hiring new directors. Second, our concept of well-connectedness is relational. How well-connected a board is in the network, and therefore what net economic benefits may be derived, depends on how other boards are connected to each other. An individual firm has limited (if any) control over director appointments in other firms, which can critically impact the relative breadth in its board network. Thus, we would not expect all firms to either desire to or have much ability to increase its boardroom network centrality.

Overall, our results are consistent with the hypothesis that being better-connected in boardroom networks allows for better access to information, capital, or other resources in response 
to timely investment opportunities or when circumstances become dire. These results are broadly consistent with the existing research that examines specific mechanisms through which social networks may benefit firms. For example, Engelberg, Gao, and Parsons (2010) find that firms with social connections to banks benefit through substantial discounts in lending rates as well as larger loan amounts and fewer restrictive covenants, Faccio (2006) finds that firms that establish political connections experience a positive return to shareholder value, and Faccio, McConnell, and Masulis (2006) find that politically connected firms are significantly more likely to be bailed out compared to non-connected firms. These types of network effects provide a rich research setting for understanding many accounting and corporate finance choices and associated performance outcomes for firms. 


\section{References}

Adamic, L., 1999. The Small World Web. In: Proceedings of the ECDL. Lecture Notes in Computer Science. Springer-Verlag, Berlin, Germany, pp. 1696.

Armstrong, C., Larcker, D., 2009. Discussion of 'The Impact of the Options Backdating Scandal on Shareholders' and 'Taxes and the backdating of stock option exercise date'. Journal of Accounting and Economics 47, 50-58.

Ballester, Coralio, Antoni Calvo-Armengol, and Yves Zenou (2006). "Who's who in networks. Wanted: The key players," Econometrica 74, 1403-1417.

Bavelas, A., 1950. Communication Patterns in Task-Oriented Groups. Journal of the Acoustical Society of America 22, 271-282.

Bebchuk, L. A., Cohen, A., Ferrell, A., 2009. What Matters in Corporate Governance. Review of Financial Studies 22, 783-827.

Bebchuk, L. A., Cohen, A., Wang, C. C.Y., 2012. Learning and the Disappearing Association between Governance and Returns. Journal of Financial Economics, Forthcoming.

Beckman, C. M., Haunschild, P. R, Phillips, D. J., 2004. Friends or Strangers? Firm-specific Uncertainty, Market Uncertainty, and Network Partner Selection. Organization Science 15, 259_ 275.

Bernile, G., Jarrell, G., 2009. The Impact of the Options Backdating Scandal on Shareholders. Journal of Accounting and Economics 47, 2-26.

Bertrand, M, Kramarz, F., Schoar, A., Thesmar, D., 2006. Politicians, Firms and the Political Business Cycle: Evidence from France. University of Chicago, et al., working paper.

Bizjak, J., Lemmon, M., Whitby, R., 2009. Option Backdating and Board Interlocks. Reveiew of Financial Studies 22, 4821-4847.

Bonacich, P., 1972. Factoring and Weighting Approaches to Status Scores and Clique Identification. Journal of Mathematical Sociology 2, 113-120.

Borgatti, Stephen P. (2005). “Centrality and network flow,” Social Networks 27, 55-71.

Borgatti, Stephen P. and Martin G. Everett (2006). "A graph-theoretic perspective on centrality," Social Networks 28, 466-484.

Bourdieu, P., 1986. Forms of Capital. In: Handbook of Theory and Research for the Sociology of Education, Richardson, J. G., ed. Greenwood Press, Westport, CT.

Boyd, B., 1990. Corporate Linkages and Organizational Environment: A Test of the Resource Dependence Model. Strategic Management Journal 11, 419-430. 
Brown, L., 2001. A Temporal Analysis of Earnings Surprises: Profits versus Losses. Journal of Accounting Research 39, 221-241.

Chan, L., Dimmock, S., Lakonishok, J., 2010. Benchmarking Money Manager Performance: Issues and Evidence. Review of Financial Studies 22, 4553-4599.

Cohen, L., A. Frazzini, A., Malloy, C., 2008. The Small World of Investing: Board Connections and Mutual Fund Managers. Journal of Political Economy 116, 951-979.

Cohen, L., Frazzini, A., Malloy, C., 2010. Sell-side School Ties. Journal of Finance, Forthcoming.

Coleman, J. S., 1988. Social Capital in the Creation of Human Capital, Supplement: Organization and Intuitions: Sociological and Economic Approaches to the Analysis of Social Structure. American Journal of Sociology 94, S95-S120.

Core, J., Holthausen, R., Larcker, D., 1999. Corporate governance, chief executive officer compensation, and firm performance. Journal of Financial Economics 51, 371-406.

Daniel, K., Grinblatt, M., Titman, S., Wermers, R., 1997. Measuring Mutual Fund Performance with Characteristic-Based Benchmarks. Journal of Finance 52, 1035-1058.

Davis, G. F., Yoo, M., Baker, W. E., 2003. The Small World of the American Corporate Elite 19822001. Strategic Organization 3, 301-326.

Demarzo, Peter M., Dimitri Vyanos, and Jeffrey Zwiebel (2003). "Persuasion bias, social influence, and unidimensional opinions," Quarterly Journal of Economics 118: 909-968.

Dooley, P. C., 1969. The Interlocking Directorate. American Economic Review 59, 314-323.

Engelberg, J., Gao, P., Parsons, C., 2012a. The Price of a CEO’s Rolodex. Review of Financial Studies, Forthcoming.

Engelberg, J., Gao, P., Parsons, C., 2012b. Friends with Money. Journal of Financial Economics 103, 169-188.

Faccio, M., 2006. Politically Connected Firms. American Economic Review 96, 369-386.

Faccio, M., McConnell, J., Masulis, R., 2006. Political Connections and Corporate Bailouts. The Journal of Finance 61, 2597-2635.

Fich, E., Shivdasani, A., 2006. Are Busy Boards Effective Monitors? The Journal of Finance 61, 689724.

Fich, E., White, L., 2003. CEO Compensation and Turnover: The Effects of Mutually Interlocked Boards. Wake Forrest Law Review 38, 935-960.

Fisman, R., Fisman, D., Galef, J., Khurana, R., 2006. Estimating the Value of Connections to VicePresident Cheney. Manuscript. 
Freeman, L. C., 1977. A Set of Measures of Centrality Based on Betweenness. Sociometry 40, 35-41.

Galaskiewicz, J., 1985. Social Organization of an Urban Grants Economy. Sage Publishing, Newbury Park, CA.

Goldman, E., Rocholl, J., So, J., 2006. Do Politically Connected Boards Affect Firm Value. AFA 2007 Chicago Meetings Paper.

Gompers, P., Ishii, J., Metrick, A., 2003. Corporate Governance and Equity Prices. Quarterly Journal of Economics 118, 107-155.

Gow, I. D., Ormazabal, G.,Taylor, D. J., 2010. Correcting for Cross-Sectional and Time-Series Dependence in Accounting Research. The Accounting Review 85, 483-512.

Granovetter, M., 1974. Getting a Job. Harvard University Press, Cambridge, MA.

Grossman, J. W., 2002,,The Evolution of the Mathematical Research Collaboration Graph. Proceedings of the $33^{\text {rd }}$ Southeastern Conference on Combinatorics, (Congressus Numberantium, 158).

Hahn, J., Lee, H., 2009. Financial Constraints, Debt Capacity, and the Cross-section of Stock Returns. Journal of Finance 64, 891-921.

Hallock, K., 1997. Reciprocally interlocking boards of directors and executive compensation. Journal of Financial and Quantitative Analysis 32, 331-344.

Haunschild, P.M., Beckman, C. M., 1998. When do interlocks matter?: Alternate sources of information and interlock influence. Administrative Science Quarterly 43, 815-844.

Hillman, A., Zardkoohi, A., Bierman, L., 1999. Corporate Political Strategies and Firm Performance: Indications of Firm-Specific Benefits from Personal Service in the U.S. Government. Strategic Management Journal 20, 67-81.

Hochberg, Y. V., Ljungqvist, A., Lu, Y., 2007. Whom You Know Matters: Venture Capital Networks and Investment Performance. Journal of Finance 62, 251-301.

Hong, H., Kubik, J., Stein, J., 2004. Social Interaction and Stock Market Performance. Journal of Finance 59, 137-163.

Hong, H., Kubik, J., Stein, J., 2005. Thy Neighbor's Portfolio: Word-of-Mouth Effects in the Holdings and Trades of Money Managers. Journal of Finance 60, 2801-2824.

Hwang, B.H., Kim, S., 2009. It pays to have friends. Journal of Financial Economics 93, 138-158.

Jackson, M., 2007. Social and Economic Networks. Princeton University Press, Princeton, NJ. 
Jenter, D., Lewellen, K., Warner, J., 2012. Security Issue Timing: What Do Managers Know and When Do They Know It?" Journal of Finance 66, 413-443.

Kapferer, B., 1969. Norms and the Manipulation of Relationships in a Work Context. In: , Mitchell, J. C. (Ed.) Social Networks in Urban Settings. Manchester University Press, Manchester, UK.

Kuhnen, C., 2009. Business Networks, Corporate Governance, and Contracting in the Mutual Fund Industry. Journal of Finance 44, 2185-2220.

Laumann, E. O., Marsden, P. V., Galaskiewicz, J., 1977. Community-elite influence structures: Extensions of a Network Approach. American Journal of Sociology 83, 594-631.

Levine, J. H., 1972. The Sphere of Influence. American Sociological Review, 37, 14-27.

Loderer, C., Peyer, U., 2002. Board Overlap, Seat Accumulation and Share Prices. European Financial Management 8, 165-192.

Masulis, Ronald W. and H. Shawn Mobbs (2012). "Independent Director Incentives: Where do Talented Directors Spend Their Time and Energy?" Working Paper.

Mizruchi, M., 1990. What Do Interlocks Do? An Analysis, Critique, and Assessment of Research on Interlocking Directorates. Annual Review of Sociology 8, 16-32.

Minton B. A., Schrand, C., Walther, B. R., 2002. The Role of Volatility in Forecasting. Review of Accounting Studies 7, 195-215.

Mol, M., 2001. Creating Wealth through Working with Others: Interorganizational Relationships. The Academy of Management Executive 15, 150-152.

Myers, C., Schultz, G., 1951. The Dynamics of a Labor Market. Prentice-Hall, Inc., New York, NY.

Newman, M. E.J., 2003. The Structure and Foundation of Complex Networks. SLAM Review 45, $167-256$.

Nicholson, G., Alexander, M., Kiel, G., 2004.Defining the Social Capital of the Board of Directors: An Exploratory Study. Journal of Management and Organization 10, 54-72.

Non, M., Franses, P. H., 2007. Interlocking Boards and Firm Performance: Evidence from a New Panel Database. Tinbergen Institute Discussion Paper No. 07-034/2, working paper.

Padgett, J. F., Ansell, C. K., 1993. Robust Action and the Rise of the Medici, 14001434. American Journal of Sociology 98, 1259-1319.

Palmer, D., Friedland, R., Singh, J., 1986. The Ties that Bind: Organizational and Class Bases of Stability in a Corporate Interlock Network. American Sociological Review 51, 781-796.

Pennings, J., 1980. Interlocking Directorates. Josey-Bass Publishers, San Francisco, CA. 
Peterson, M. A., 2009. Estimating Standard Errors in Finance Panel Data Sets: Comparing Approaches. Review of Financial Studies 22, 435-480.

Pfeffer, J., Salancik, G. R., 1978. The External Control of Organizations: A Resource Dependence Perspective. In: , Harper and Row., Rees, Albert and G. Shultz, 1970, Workers and Wages in an Urban Labor Union. University of Chicago Press, Chicago, IL.

Santos, R. L., da Silveira, A. M., Barros, A. B. C., 2009. Board Interlocking in Brazil: Directors' Participation in Multiple Companies and its Effect on Firm Value. Working Paper.

Schoorman, F.D., Bazerman, M. H., Atkin, R. S., 1981,.Interlocking Directorates: A Strategy for Reducing Environmental Uncertainty. Academy of Management Review 6, 243-251.

Shumway, T., 1996. The Delisting Bias in CRSP Data. Journal of Finance 52, 327-340.

Snyder, P. J., Priem, R. L., Levitas, E., 2009, The Diffusion of Illegal Innovations Among Management Elites. The Academy of Management Proceedings, 2009.

So, E., 2012, A New Approach to Predicting Analyst Forecast Errors: Do Investors Overweight Analyst Forecasts? Journal of Financial Economics, Forthcoming.

Stuart, T. E., Yim, S., 2010. Board Interlocks and the Propensity to be Targeted in Private Equity Transactions. Journal of Financial Economics 97, 174-189.

Thompson, S. B., 2011. Simple Formulas for Standard Errors that Cluster by Both Firm and Time. Journal of Financial Economics 99, 1-10.

Watts, D. J., 1999. Small Worlds: The Dynamics of Networks between Order and Randomness. Princeton University Press, Princeton, NJ.

Westphal, J. D., Boivie, S., Chng, D. H. M., 2006. The Strategic Impetus for Social Network Ties: Reconstituting Broken CEO Friendship Ties. Strategic Management Journal 27, 245-445.

Zhang, X. F., 2006. Information Uncertainty and Stock Returns. Journal of Finance 61, 105-137. 


\section{Figure 1}

\section{Distribution of Degree Centrality of Board Network}

The figure below displays the annual distribution of degree centrality for the aggregate boardroom network. The boxplots provide the min, $\max$, and several percentiles of the distribution. The box represents the interquartile range, where the line in the center of the box represents the median of the distribution. The endpoints of the whiskers around the box represent the $5^{\text {th }}$ and $95^{\text {th }}$ percentiles of the distribution. The network is comprised of all firms covered in the Board Member Magazine Director Database. Degree centrality is defined as the number of first degree links that a firm possesses to unique outside boards.

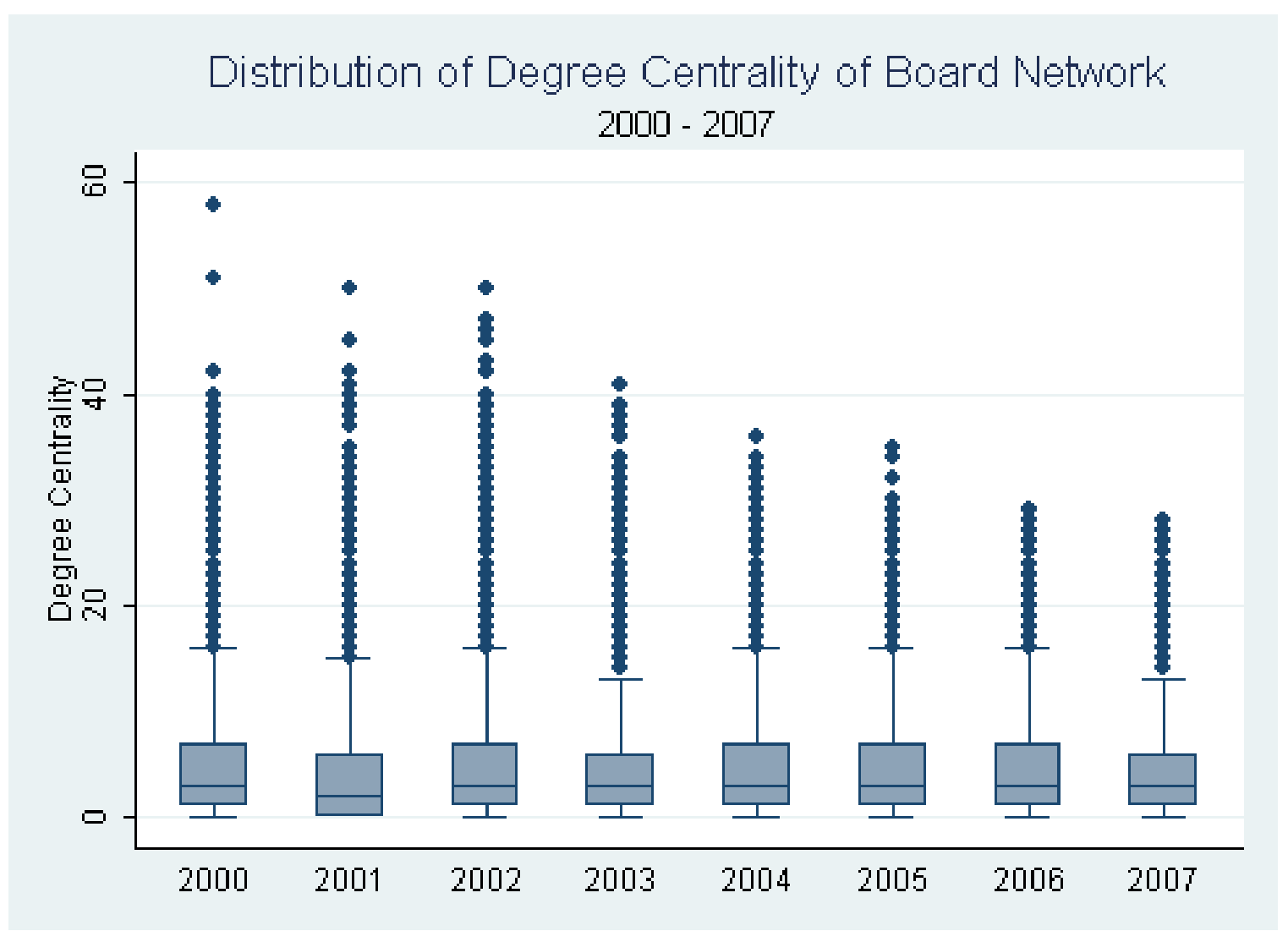


Table 1

Boardroom Network Summary Statistics

Panel A provides annual summary statistics of the aggregate boardroom network. A component is a subset of the network that is connected; that is, any node or firm in a component can reach any other node in the component through links. Isolated firms are those nodes, which have no connections to any other nodes in the network. Panel B contains summary statistics for the central component of the boardroom network. Average path length is the average shortest number of steps separating two firms. Diameter is the longest number of steps separating any two firms in the central component. Clustering coefficient describes the percent of boardroom links that would arise from a network consisting of the same number of nodes and the same expected number of edges, by simulating such networks 1,000 times and computing the clustering coefficient in each. Panel C provides the firm-specific average number of first-degree network links in each year of the sample, where first-degree links are defined as two companies sharing at least one board of directors.

\begin{tabular}{|c|c|c|c|c|c|c|c|c|}
\hline \multicolumn{9}{|c|}{ Panel A: Summary Statistics of Boardroom Network Characteristics } \\
\hline Year & 2000 & 2001 & 2002 & 2003 & 2004 & 2005 & 2006 & 2007 \\
\hline \#Firms & 7,594 & 7,527 & 6,998 & 6,303 & 6,103 & 6,100 & 6,072 & 6,066 \\
\hline \#Links & 25,623 & 24,167 & 23,925 & 20,210 & 19,688 & 19,833 & 19,508 & 19,092 \\
\hline \#Directors & 56,444 & 52,673 & 54,388 & 51,382 & 51,103 & 52,321 & 52,375 & 52,265 \\
\hline Size of Largest Component & 5,424 & 5,180 & 5,003 & 4,474 & 4,374 & 4,494 & 4,469 & 4,428 \\
\hline$(\%)$ & $71 \%$ & $69 \%$ & $71 \%$ & $71 \%$ & $72 \%$ & $74 \%$ & $74 \%$ & $73 \%$ \\
\hline Size of Second Largest & & & & & & & & \\
\hline Component & 7 & 6 & 5 & 10 & 5 & 6 & 7 & 9 \\
\hline$(\%)$ & $0.09 \%$ & $0.08 \%$ & $0.07 \%$ & $0.16 \%$ & $0.08 \%$ & $0.10 \%$ & $0.12 \%$ & $0.15 \%$ \\
\hline \# Isolated Firms & 1797 & 2004 & 1726 & 1526 & 1448 & 1398 & 1386 & 1401 \\
\hline$(\%)$ & $24 \%$ & $27 \%$ & $25 \%$ & $24 \%$ & $24 \%$ & $23 \%$ & $23 \%$ & $23 \%$ \\
\hline
\end{tabular}

\begin{tabular}{r|rrrrrrrr}
\hline \multicolumn{1}{l}{ Panel B: Summary Statistics of Central Component } \\
\hline Year & $\mathbf{2 0 0 0}$ & $\mathbf{2 0 0 1}$ & $\mathbf{2 0 0 2}$ & $\mathbf{2 0 0 3}$ & $\mathbf{2 0 0 4}$ & $\mathbf{2 0 0 5}$ & $\mathbf{2 0 0 6}$ & $\mathbf{2 0 0 7}$ \\
\hline Avg Path Length & 5.40 & 5.42 & 5.22 & 5.36 & 5.34 & 5.39 & 5.42 & 5.49 \\
Diameter & 20 & 16 & 15 & 15 & 16 & 15 & 15 & 17 \\
Clustering Coeff & 0.21 & 0.21 & 0.19 & 0.19 & 0.18 & 0.18 & 0.17 & 0.17 \\
99\% CI of Simulated Random & $(0.0006$, & $(0.0005$, & $(0.0006$, & $(0.0006$, & $(0.0007$, & $(0.0007$, & $(0.0007$, & $(0.0006$, \\
Network Clustering Coeff $(*)$ & $0.0012)$ & $0.0011)$ & $0.0012)$ & $0.0013)$ & $0.0014)$ & $0.0014)$ & $0.0014)$ & $0.0014)$ \\
\hline
\end{tabular}

\begin{tabular}{r|rrrrrrrr}
\hline Panel C: Summary Statistics of DEGREE Centrality & & & & & \\
\hline Year & $\mathbf{2 0 0 0}$ & $\mathbf{2 0 0 1}$ & $\mathbf{2 0 0 2}$ & $\mathbf{2 0 0 3}$ & $\mathbf{2 0 0 4}$ & $\mathbf{2 0 0 5}$ & $\mathbf{2 0 0 6}$ & $\mathbf{2 0 0 7}$ \\
\hline Avg Degree & 4.75 & 4.42 & 4.84 & 4.41 & 4.45 & 4.50 & 4.43 & 4.30 \\
Avg Degree of Largest Comp & 6.56 & 6.34 & 6.71 & 6.13 & 6.13 & 6.05 & 5.95 & 5.82 \\
\hline
\end{tabular}


Table 2

Sample Statistics

Panel A provides the number of firms and sample averages for each year of the 2000-2007 sample. All centrality measures (DEGREE, CLOSENESS, BETWEENNESS, and

EIGENVECTOR) are detailed in Section 3.2. Note that these are the raw network measures. SIZE equals the log of market capitalization and LBM equals the log of 1 plus the firm's

book-to-market ratio, where both are measured using the firm's most recent annual financial statement prior to June $30^{\text {th }}$ of a given year. Panel B contains the pooled sample averages by industry, where industries are grouped by two-digit GICs industry codes. Panel C presents pooled descriptive statistics. ROA is the firm's net income scaled by lagged assets, AGE is the $\log$ of the number of prior months that the firm appears in CRSP, and ASSETS is the log of total assets.

\begin{tabular}{|c|c|c|c|c|c|c|c|}
\hline \multicolumn{8}{|c|}{ Panel A: Firm Counts and Sample Averages by Year } \\
\hline & OBS & DEGREE & CLOSENESS & BETWEENNESS & EIGENVECTOR & SIZE & $\mathrm{LBM}$ \\
\hline 2000 & 3,896 & 5.214 & 0.037 & 9.800 & 0.022 & 12.312 & 0.558 \\
\hline 2001 & 3,704 & 5.108 & 0.035 & 9.583 & 0.019 & 12.440 & 0.491 \\
\hline 2002 & 3,679 & 5.606 & 0.042 & 9.198 & 0.027 & 12.534 & 0.533 \\
\hline 2003 & 3,662 & 4.992 & 0.045 & 8.271 & 0.039 & 12.895 & 0.398 \\
\hline 2004 & 3,656 & 5.013 & 0.048 & 7.857 & 0.038 & 13.008 & 0.370 \\
\hline 2005 & 3,710 & 4.988 & 0.052 & 8.215 & 0.033 & 13.118 & 0.380 \\
\hline 2006 & 3,704 & 4.995 & 0.052 & 8.405 & 0.054 & 13.244 & 0.374 \\
\hline 2007 & 3,626 & 4.934 & 0.051 & 8.712 & 0.046 & 12.951 & 0.440 \\
\hline All & 29,637 & 5.107 & 0.045 & 8.764 & 0.035 & 12.809 & 0.444 \\
\hline \multicolumn{8}{|c|}{ Panel B: Firm Counts and Sample Averages by Industry } \\
\hline & OBS & DEGREE & CLOSENESS & BETWEENNESS & EIGENVECTOR & SIZE & $\mathrm{LBM}$ \\
\hline Energy & 1,369 & 5.159 & 0.046 & 8.831 & 0.032 & 13.546 & 0.404 \\
\hline Materials & 1,272 & 7.383 & 0.048 & 13.394 & 0.067 & 13.202 & 0.490 \\
\hline Industrials & 4,045 & 5.602 & 0.048 & 9.640 & 0.042 & 12.680 & 0.479 \\
\hline Con. Discret. & 4,720 & 5.256 & 0.047 & 8.445 & 0.039 & 12.822 & 0.482 \\
\hline Con.Staples & 1,236 & 6.483 & 0.044 & 12.951 & 0.065 & 13.171 & 0.410 \\
\hline Health Care & 4,075 & 6.066 & 0.050 & 9.819 & 0.031 & 12.776 & 0.305 \\
\hline Financials & 6,131 & 2.901 & 0.034 & 5.103 & 0.023 & 12.560 & 0.525 \\
\hline Info. Tech. & 5,656 & 5.144 & 0.049 & 8.731 & 0.023 & 12.623 & 0.405 \\
\hline Telecom & 385 & 6.179 & 0.048 & 11.914 & 0.054 & 13.354 & 0.383 \\
\hline Utilities & 748 & 7.282 & 0.050 & 14.001 & 0.060 & 14.154 & 0.474 \\
\hline
\end{tabular}


Table 2: [Continued]

\begin{tabular}{|c|c|c|c|c|c|c|}
\hline \multicolumn{7}{|c|}{ Panel C: Descriptive Statistics of Firm Characteristics } \\
\hline & MEAN & STDEV & P25 & MEDIAN & P75 & SKEW \\
\hline DEGREE & 5.107 & 5.667 & 1.000 & 3.000 & 7.000 & 1.734 \\
\hline CLOSENESS & 0.045 & 0.018 & 0.043 & 0.050 & 0.061 & -0.842 \\
\hline BETWEENNESS & 8.764 & 15.381 & 0.000 & 2.045 & 10.796 & 3.005 \\
\hline EIGENVECTOR & 0.035 & 0.082 & 0.000 & 0.003 & 0.027 & 3.971 \\
\hline SIZE & 12.809 & 1.970 & 11.351 & 12.720 & 14.105 & 0.288 \\
\hline LBM & 0.444 & 0.275 & 0.259 & 0.406 & 0.573 & 1.179 \\
\hline ROA & -0.013 & 0.398 & -0.003 & 0.023 & 0.075 & -39.699 \\
\hline AGE & 199.6 & 181.7 & 76.0 & 139.0 & 263.0 & 1.908 \\
\hline ASSETS & 6.146 & 2.009 & 4.721 & 6.090 & 7.427 & 0.292 \\
\hline
\end{tabular}


Table 3

Correlation Table

Panel A contains the average of annual cross-sectional correlations of the raw network measures, SIZE, and LBM, where Pearson (Spearman) correlations are shown above (below) the diagonal. All centrality measures (DEGREE, CLOSENESS, BETWEENNESS, and EIGENVECTOR) are detailed in Section 3.2. SIZE equals the log of market capitalization and LBM equals the log of 1 plus the firm's book-to-market ratio, where both are measured using the firm's most recent annual financial statement prior to June $30^{\text {th }}$ of a given year. Panel B contains average correlations when firms are first sorted by year and second within size quintiles. Average annual correlations are calculated within each size quintile and then averaged across quintiles. Quintile ranks of DEGREE, CLOSENESS, BETWEENNESS, and EIGENVECTOR are formed each June using the centrality measures from the most recent year, where firms with higher (lower) centrality are assigned a rank of 5 (1). N-Score equals the average quintile rank of the four centrality measures, rounded to the nearest integer. Panel C contains principal component analysis of the four centrality measures. Panel D contains descriptive statistics of firm characteristics across quintiles of N-Score. MOMEN is the firm's market-adjusted returns over the 12 months prior to portfolio formation, ROA is the firm's net income scaled by lagged assets, AGE is the log of the number of prior months that the firm appears in CRSP, and ASSETS is the log of total assets.

\begin{tabular}{lccccc}
\hline \multicolumn{2}{l}{ Panel A: Pearson (Spearman) Correlations Above (Below) Diagonal } & & & \\
\hline & DEGREE & CLOSENESS & BETWEENNESS & EIGENVECTOR & SIZE \\
DEGREE & & 0.494 & 0.898 & 0.811 & 0.619 \\
CLOSENESS & 0.940 & & 0.325 & 0.242 & 0.388 \\
BETWEENNESS & 0.919 & 0.854 & & 0.764 & -0.184 \\
EIGENVECTOR & 0.913 & 0.987 & 0.830 & 0.546 & 0.545 \\
SIZE & 0.580 & 0.610 & 0.558 & -0.599 & -0.146 \\
LBM & -0.215 & -0.216 & -0.192 & -0.207 & -0.379 \\
\hline
\end{tabular}

Panel B: Average Size-Adjusted Pearson (Spearman) Correlations Above (Below) Diagonal

\begin{tabular}{lccccc}
\hline Panel B: Average Size-Adjusted Pearson (Spearman) Correlations Above (Below) Diagonal & & \\
\hline & DEGREE & CLOSENESS & BETWEENNESS & EIGENVECTOR & SIZE \\
\cline { 2 - 7 } DEGREE & & 0.493 & 0.827 & 0.686 & 0.204 \\
CLOSENESS & 0.916 & & 0.307 & 0.235 & 0.089 \\
BETWEENNESS & 0.872 & 0.777 & & 0.576 & 0.005 \\
EIGENVECTOR & 0.867 & 0.973 & 0.740 & 0.201 & 0.174 \\
SIZE & 0.188 & 0.204 & 0.177 & 0.012 & -0.02 \\
LBM & -0.005 & 0.005 & 0.009 & -0.117 & \\
\hline
\end{tabular}


Table 3: [Continued]

\begin{tabular}{lcccc}
\hline Panel C: Principle Components Analysis & & & \\
\hline & Comp. 1 & Comp. 2 & Comp. 3 & Comp. 4 \\
\cline { 2 - 5 } DEGREE & 0.578 & -0.049 & -0.266 & -0.770 \\
CLOSENESS & 0.311 & 0.936 & 0.069 & 0.150 \\
BETWEENNESS & 0.549 & -0.242 & -0.521 & 0.607 \\
EIGENVECTOR & 0.517 & -0.252 & 0.808 & 0.126 \\
& & & & \\
Eigenvalue & 2.774 & 0.831 & 0.312 & 0.826 \\
\% Var Explained & $69.35 \%$ & $20.77 \%$ & $7.81 \%$ & $2.06 \%$ \\
Cumulative \% & $69.35 \%$ & $90.12 \%$ & $97.93 \%$ & $100 \%$ \\
\hline
\end{tabular}

\begin{tabular}{|c|c|c|c|c|c|c|c|}
\hline \multicolumn{8}{|c|}{ Panel D: Firm Characteristics Across Quintiles of Centrality } \\
\hline & \multicolumn{5}{|c|}{ N-Score } & \multirow[b]{2}{*}{ High-Low } & \multirow[b]{2}{*}{$\begin{array}{c}\mathrm{t}-\text { Stat } \\
\text { (High-Low) }\end{array}$} \\
\hline & 1 (Low) & 2 & 3 & 4 & 5 (High) & & \\
\hline SIZE & 12.959 & 12.026 & 12.906 & 12.764 & 12.905 & -0.054 & $-(3.803)$ \\
\hline LBM & 0.401 & 0.450 & 0.398 & 0.408 & 0.418 & 0.016 & $(4.590)$ \\
\hline MOMEN & 0.149 & 0.078 & 0.064 & 0.030 & -0.007 & -0.155 & $-(3.705)$ \\
\hline $\mathrm{ROA}$ & 0.027 & 0.022 & 0.032 & 0.024 & 0.015 & -0.012 & $-(1.621)$ \\
\hline AGE & 4.882 & 4.876 & 4.933 & 4.964 & 5.034 & 0.152 & $-(0.268)$ \\
\hline ASSETS & 6.594 & 5.710 & 6.043 & 5.911 & 6.302 & -0.292 & $-(6.313)$ \\
\hline
\end{tabular}


Table 4

Return Prediction

Panel A contains the results from regressing firm-specific one-year-ahead characteristic-adjusted returns (RET1Y) on the quintile ranks of five measures of board centrality. Descriptions of DEGREE, CLOSENESS, BETWEENNESS, and EIGENVECTOR are detailed in Section 3.2. Quintile ranks are formed each June using the centrality measures from the most recent year, where firms with higher (lower) centrality are assigned a rank of 5 (1). N-Score equals the average quintile rank of the four centrality measures, rounded to the nearest integer. Industry and year fixed-effects are included throughout. In Panel A, the t-statistics based on two-way (firm and year) cluster robust standard errors are shown in parentheses. Levels of significance are indicated by $*, * *$, and $* * *$ for $10 \%, 5 \%$, and $1 \%$, respectively. Panel B contains the equal-weighted average of one-year-ahead average characteristic-adjusted return by industry, where industries are grouped by two-digit GICs industry codes. Characteristic-adjusted returns are calculated as of July $1{ }^{\text {st }}$ of each year as the difference between a firm's cumulative return and the value-weighted average portfolio of firms matched by size, book-tomarket, and momentum, where both returns are measured over identical holding periods. In Panel B, the t-statistics are based on Monte Carlo simulations by forming annual empirical reference distributions that randomly assign all firms to quintiles, by matching the observational counts in each N-Score quintile. We simulate 1,000 portfolios for each year and calculate the average long-short difference for each simulated portfolio. We calculate and report average bootstrap t-statistics by contrasting the realized annual hedge returns against the empirical reference distributions.

\begin{tabular}{|c|c|c|c|c|c|}
\hline \multicolumn{6}{|c|}{ Panel A: Regression Results of One-Year-Ahead Characteristic-Adjusted Returns (RET1Y) } \\
\hline \multirow{3}{*}{ Quintile(DEGREE) } & (1) & $(2)$ & (3) & (4) & $(5)$ \\
\hline & $0.010 * * *$ & - & - & - & - \\
\hline & $(2.83)$ & - & - & - & - \\
\hline \multirow[t]{2}{*}{ Quintile(CLOSENESS) } & - & $0.012^{* * *}$ & - & - & - \\
\hline & - & $(3.45)$ & - & - & - \\
\hline \multirow{2}{*}{ Quintile(BETWEENNESS) } & - & - & $0.007^{* *}$ & - & - \\
\hline & - & - & $(1.99)$ & - & - \\
\hline \multirow[t]{2}{*}{ Quintile(EIGENVECTOR) } & - & - & - & $0.009 * *$ & - \\
\hline & - & - & - & $(2.56)$ & - \\
\hline \multirow[t]{2}{*}{ N-Score } & - & - & - & - & $0.011 * * *$ \\
\hline & - & - & - & - & (3.03) \\
\hline \multirow[t]{2}{*}{ Intercept } & 0.007 & 0.003 & 0.012 & 0.009 & 0.008 \\
\hline & $(0.17)$ & $(0.08)$ & $(0.29)$ & $(0.23)$ & $(0.20)$ \\
\hline $\mathrm{R}$-square & 0.006 & 0.006 & 0.005 & 0.005 & 0.006 \\
\hline Obs & 29,637 & 29,637 & 29,637 & 29,637 & 29,637 \\
\hline
\end{tabular}

\begin{tabular}{lccccccc}
\hline \multicolumn{7}{c}{ Panel B: Equal-Weighted Average One-Year-Ahead Characteristic-Adjusted Returns by Industry } \\
\cline { 2 - 7 } & \multicolumn{7}{c}{ N-Score } \\
& 1 (Low) & 2 & 3 & 4 & 5 (High) & $\begin{array}{c}\text { Hedge } \\
\text { (High-Low) }\end{array}$ & $\begin{array}{c}\text { t-Stat } \\
\text { (High-Low) }\end{array}$ \\
\cline { 2 - 7 } & & & & & & & \\
All & -0.0116 & -0.0006 & 0.0206 & 0.0250 & 0.0371 & 0.0486 & $(4.394)$ \\
Energy & & & & & & & $(0.684)$ \\
Materials & 0.0639 & 0.1172 & 0.1717 & 0.1827 & 0.1177 & 0.0538 & $-(0.361)$ \\
Industrials & 0.0735 & 0.0048 & 0.0710 & 0.0091 & 0.0547 & -0.0189 & $(1.816)$ \\
Consumer Discretionary & -0.0128 & 0.0192 & 0.0383 & 0.0395 & 0.0521 & 0.0650 & $(0.421)$ \\
Consumer Staples & -0.0453 & -0.0223 & -0.0214 & -0.0242 & -0.0328 & 0.0124 & $-(0.166)$ \\
Health Care & 0.0806 & 0.0292 & 0.0710 & 0.0687 & 0.0702 & -0.0104 & $(1.377)$ \\
Financials & 0.0059 & 0.0251 & 0.0209 & 0.0434 & 0.0518 & 0.0459 & $(1.476)$ \\
Information Technology & -0.0259 & -0.0266 & -0.0177 & -0.0134 & 0.0070 & 0.0329 & $(2.779)$ \\
Telecom Services & -0.0236 & -0.0119 & 0.0148 & 0.0206 & 0.0659 & 0.0895 & $-(0.611)$ \\
Utilities & -0.0699 & -0.0634 & -0.0507 & 0.2431 & -0.1253 & -0.0554 & $(1.183)$ \\
\hline
\end{tabular}


Table 5

Yearly Characteristic-Adjusted Returns

Panel A (B) contains annual one-year (two-year) ahead cumulative characteristic-adjusted returns to quintiles of N-Score. N-Score equals the average quintile rank of the four centrality measures, rounded to the nearest integer. Descriptions of the four centrality measures DEGREE, CLOSENESS, BETWEENNESS, and EIGENVECTOR are detailed in Section 3.2. Quintile ranks are formed each June using the centrality measures from the most recent year, where firms with higher (lower) centrality are assigned a rank of 5 (1). t-statistics based on robust standard errors, clustered by firm, are shown in parentheses. The year shown on the left-hand column indicates the vintage of the Board Member Magazine database, where portfolios are formed at the end of June of the subsequent year. Characteristic-adjusted returns are calculated as of July $1^{\text {st }}$ as the difference between a firm's cumulative return and the value-weighted average portfolio of firms matched by size, book-to-market, and momentum, where both returns are measured over identical holding periods. t-statistics are based on Monte Carlo simulations by forming annual empirical reference distributions that randomly assign all firms to quintiles, by matching the observational counts in each N-Score quintile. We simulate 1,000 portfolios for each year and calculate the average long-short difference for each simulated portfolio. We calculate and report average bootstrap t-statistics by contrasting the realized annual hedge returns against the empirical reference distributions.

\begin{tabular}{|c|c|c|c|c|c|c|c|}
\hline \multicolumn{8}{|c|}{ Panel A: Annual Average One-Year-Ahead Characteristic-Adjusted Returns by N-Score } \\
\hline & \multicolumn{5}{|c|}{ N-Score } & \multirow[b]{2}{*}{$\begin{array}{c}\text { Hedge } \\
\text { (High-Low) }\end{array}$} & \multirow[b]{2}{*}{$\begin{array}{c}\text { t-Stat } \\
\text { (High-Low) }\end{array}$} \\
\hline & 1 (Low) & 2 & 3 & 4 & 5 (High) & & \\
\hline 2000 & 0.0220 & 0.0164 & 0.0342 & 0.0317 & 0.0559 & 0.0339 & $(1.011)$ \\
\hline 2001 & 0.0186 & -0.0340 & 0.0050 & -0.0090 & 0.0357 & 0.0171 & $(0.420)$ \\
\hline 2002 & -0.0546 & -0.0167 & 0.0522 & 0.0559 & 0.0610 & 0.1156 & (2.723) \\
\hline 2003 & 0.0224 & 0.0387 & 0.0254 & 0.0133 & 0.0591 & 0.0367 & (1.331) \\
\hline 2004 & -0.0178 & -0.0151 & 0.0259 & 0.0346 & 0.0429 & 0.0608 & (2.078) \\
\hline 2005 & -0.0717 & -0.0041 & 0.0011 & 0.0304 & 0.0493 & 0.1210 & (4.419) \\
\hline 2006 & 0.0118 & 0.0207 & -0.0083 & 0.0046 & -0.0403 & -0.0521 & $-(2.001)$ \\
\hline 2007 & -0.0065 & -0.0185 & 0.0289 & 0.0386 & 0.0345 & 0.0410 & $(1.504)$ \\
\hline All & -0.0095 & -0.0016 & 0.0205 & 0.0250 & 0.0373 & 0.0468 & (4.061) \\
\hline STDEV & 0.036 & 0.024 & 0.020 & 0.021 & 0.033 & 0.055 & \\
\hline
\end{tabular}

\begin{tabular}{|c|c|c|c|c|c|c|c|}
\hline \multicolumn{8}{|c|}{ Panel B: Annual Average Two-Year Cumulative Characteristic-Adjusted Returns by N-Score } \\
\hline & \multicolumn{5}{|c|}{ N-Score } & \multirow[b]{2}{*}{$\begin{array}{c}\text { Hedge } \\
\text { (High-Low) }\end{array}$} & \multirow[b]{2}{*}{$\begin{array}{c}\text { t-Stat } \\
\text { (High-Low }\end{array}$} \\
\hline & 1 (Low) & 2 & 3 & 4 & 5 (High) & & \\
\hline 2000 & 0.0358 & 0.0595 & 0.0235 & -0.0167 & 0.0398 & 0.0040 & $(0.056)$ \\
\hline 2001 & -0.0039 & -0.0505 & 0.0352 & 0.0514 & 0.1245 & 0.1285 & (1.591) \\
\hline 2002 & -0.0024 & 0.0273 & 0.0704 & 0.0423 & 0.1145 & 0.1169 & (1.928) \\
\hline 2003 & 0.0165 & 0.0510 & 0.0307 & 0.0511 & 0.0952 & 0.0788 & (1.601) \\
\hline 2004 & -0.0930 & -0.0305 & 0.0424 & 0.0665 & 0.1073 & 0.2003 & (4.538) \\
\hline 2005 & -0.0637 & -0.0090 & 0.0152 & 0.0283 & 0.0431 & 0.1068 & $(2.765)$ \\
\hline 2006 & 0.0125 & 0.0101 & 0.0039 & 0.0296 & 0.0043 & -0.0082 & $-(0.318)$ \\
\hline 2007 & -0.0486 & -0.0412 & 0.0598 & 0.0629 & 0.0676 & 0.1162 & (3.169) \\
\hline All & -0.0184 & 0.0021 & 0.0351 & 0.0394 & 0.0746 & 0.0929 & $(5.420)$ \\
\hline STDEV & 0.045 & 0.042 & 0.022 & 0.027 & 0.043 & 0.068 & \\
\hline
\end{tabular}


Table 6

Subsample Analysis of Future Returns

The table below contains the results from regressing firm-specific one-year-ahead characteristic-adjusted returns (RET1Y) on the quintile ranks of five measures of board centrality. N-Score equals the average quintile rank of the four centrality measures (DEGREE, CLOSENESS, BETWEENNESS, and EIGENVECTOR), rounded to the nearest integer. Quintile ranks are formed each June using the centrality measures from the most recent year, where higher (lower) values are assigned a rank of 5 (1). Each column in the table corresponds to the listed subsample. Growth, Young, Low ROA, and Low RET indicate that the analysis is conducted on subsamples of firms in the lowest tercile of LBM, AGE, ROA, and MOMEN, respectively. The 'Coefficient Test' contains p-values from tests of the null hypothesis that the N-Score coefficient is significantly larger than the N-Score coefficient for the non-Growth subsample. For example, the p-value of 0.0141 in Column (2) indicates that the N-Score coefficient for the Growth subsample is significantly larger than the N-Score coefficient for the non-Growth subsample (results not tabulated). LBM equals one plus the firm's book-to-market ratio, AGE is the log of the number of prior months that the firm appears in CRSP, ROA is the firm's net income scaled by lagged assets, and MOMEN is the firm's market-adjusted returns over the 12 months following portfolio formation. Characteristic-adjusted returns are calculated as of July $1^{\text {st }}$ of each year as the difference between a firm's cumulative return and the value-weighted average portfolio of firms matched by size, book-to-market, and momentum, where both returns are measured over identical holding periods. Industry and year fixed-effects are included throughout. The t-statistics based on two-way (firm and year) cluster robust standard errors are shown in parentheses. Levels of significance are indicated by *, **, and *** for $10 \%$, $5 \%$, and $1 \%$, respectively.

\begin{tabular}{lccccccc}
\hline Sample: & All & Growth & Young & Low ROA & Low Ret & $\begin{array}{c}\text { Growth \& } \\
\text { Young }\end{array}$ & $\begin{array}{c}\text { Low ROA } \\
\text { \& Low Ret }\end{array}$ \\
\cline { 2 - 8 } & $(1)$ & $(2)$ & $(3)$ & $(4)$ & $(5)$ & $(6)$ & $(7)$ \\
\cline { 2 - 8 } N-Score & $0.011^{* * *}$ & $0.019^{* * *}$ & $0.024^{* * *}$ & $0.035^{* * *}$ & $0.025^{* * *}$ & $0.034^{* * *}$ & $0.041^{* * *}$ \\
& $(3.03)$ & $(4.77)$ & $(4.77)$ & $(4.77)$ & $(4.70)$ & $(4.11)$ & $(5.49)$ \\
Intercept & 0.008 & $-0.077^{*}$ & $-0.015^{* * *}$ & $-0.023^{* * *}$ & 0.043 & 0.101 & 0.133 \\
& $(0.20)$ & $(-1.82)$ & $(-1.82)$ & $(-1.82)$ & $(0.88)$ & $(0.79)$ & $(0.80)$ \\
\hline Obs & 29,637 & 9,874 & 9,887 & 9,870 & 9,874 & 3,735 & 4,774 \\
\hline R-square & 0.006 & 0.006 & 0.007 & 0.010 & 0.009 & 0.013 & 0.012 \\
\hline Ho Coefficient Test & & 0.0141 & 0.0003 & 0.0000 & 0.0000 & 0.0004 & 0.0000 \\
\hline
\end{tabular}


Table 7

\section{Changes in Return on Assets (ROA)}

Panel A contains the results from regressing firm-specific one-year-ahead changes in ROA (i.e., FY1 ROA minus current ROA) minus the contemporaneous change in industry median ROA on the quintile ranks of five measures of board centrality. Descriptions of DEGREE, CLOSENESS, BETWEENNESS, and EIGENVECTOR are detailed in Section 3.2. Quintile ranks are formed each June using the centrality measures from the most recent year, where higher (lower) values are assigned a rank of 5 (1). N-Score equals the average quintile rank of the four centrality measures, rounded to the nearest integer. ROA is the firm's net income scaled by lagged assets, MOMEN is the firm's market-adjusted returns over the 12 months prior to portfolio formation, LBM equals one plus the firm's book-to-market ratio, SIZE equals the log of market capitalization, SALES is the log of total sales, AGE is the log of the number of months since the firm first appeared in CRSP, and ASSETS is the log of total assets. LAG $\triangle$ ROA) equals a firm's lagged change in industry-adjusted ROA. Industry and year fixed-effects are included throughout. The t-statistics based on two-way (firm and year) cluster robust standard errors are shown in parentheses. Panel B contains the results from regressing two- and three-year-ahead changes in ROA on N-Score. Levels of significance are indicated by $*, * *$, and $* * *$ for $10 \%, 5 \%$, and $1 \%$, respectively.

\begin{tabular}{|c|c|c|c|c|c|}
\hline \multicolumn{6}{|c|}{ Panel A: Regression Results of One-Year Ahead $\triangle$ ROA (i.e., FY1 ROA minus Current ROA) } \\
\hline \multirow{3}{*}{ Quintile(DEGREE) } & $(1)$ & $(2)$ & (3) & $(4)$ & $(5)$ \\
\hline & $0.005^{* *}$ & - & - & - & - \\
\hline & $(2.35)$ & - & - & - & - \\
\hline \multirow[t]{2}{*}{ Quintile(CLOSENESS) } & - & $0.005^{* * *}$ & - & - & - \\
\hline & - & $(3.02)$ & - & - & - \\
\hline \multirow[t]{2}{*}{ Quintile(BETWEENNESS) } & - & - & $0.004 * *$ & - & - \\
\hline & - & - & $(2.45)$ & - & - \\
\hline \multirow[t]{2}{*}{ Quintile(EIGENVECTOR) } & - & - & - & $0.004 * * *$ & - \\
\hline & - & - & - & $(2.82)$ & - \\
\hline \multirow[t]{2}{*}{ N-Score } & - & - & - & - & $0.005^{* * *}$ \\
\hline & - & - & - & - & $(3.00)$ \\
\hline \multirow[t]{2}{*}{$\mathrm{LAG}(\Delta \mathrm{ROA})$} & $-0.066^{*}$ & $-0.066^{*}$ & $-0.065^{*}$ & $-0.066^{*}$ & $-0.066^{*}$ \\
\hline & $(-1.89)$ & $(-1.89)$ & $(-1.88)$ & $(-1.88)$ & $(-1.89)$ \\
\hline \multirow[t]{2}{*}{ MOMEN } & $0.028 * * *$ & $0.028^{* * *}$ & $0.027 * * *$ & $0.028^{* * *}$ & $0.028^{* * *}$ \\
\hline & $(4.06)$ & $(4.04)$ & $(3.96)$ & $(4.02)$ & $(4.03)$ \\
\hline \multirow[t]{2}{*}{ LBM } & -0.002 & -0.001 & -0.002 & -0.001 & -0.002 \\
\hline & $(-0.11)$ & $(-0.08)$ & $(-0.09)$ & $(-0.07)$ & $(-0.08)$ \\
\hline \multirow[t]{2}{*}{ SIZE } & 0.007 & 0.007 & 0.006 & 0.007 & 0.007 \\
\hline & $(1.47)$ & $(1.51)$ & $(1.45)$ & $(1.49)$ & $(1.51)$ \\
\hline \multirow{2}{*}{ RND } & 0.001 & 0.001 & $0.001 *$ & 0.001 & 0.001 \\
\hline & $(1.56)$ & $(1.56)$ & $(1.75)$ & $(1.59)$ & $(1.57)$ \\
\hline \multirow[t]{2}{*}{ LVG } & $0.020 * * *$ & $0.020^{* * *}$ & $0.020 * * *$ & $0.021 * * *$ & $0.020^{* * *}$ \\
\hline & (3.16) & (3.48) & (3.39) & (3.59) & $(3.43)$ \\
\hline \multirow[t]{2}{*}{ ASSETS } & 0.004 & 0.004 & 0.004 & 0.004 & 0.003 \\
\hline & $(0.74)$ & $(0.73)$ & $(0.73)$ & $(0.74)$ & $(0.70)$ \\
\hline \multirow[t]{2}{*}{ SALES } & -0.012 & -0.012 & -0.011 & -0.012 & -0.012 \\
\hline & $(-1.36)$ & $(-1.38)$ & $(-1.34)$ & $(-1.37)$ & $(-1.37)$ \\
\hline \multirow[t]{2}{*}{ AGE } & -0.006 & -0.006 & -0.006 & -0.006 & -0.006 \\
\hline & $(-1.16)$ & $(-1.16)$ & $(-1.14)$ & $(-1.16)$ & $(-1.17)$ \\
\hline \multirow{2}{*}{ Intercept } & -0.017 & -0.019 & -0.015 & -0.019 & -0.018 \\
\hline & $(-0.82)$ & $(-0.91)$ & $(-0.72)$ & $(-0.89)$ & $(-0.85)$ \\
\hline $\mathrm{R}$-square & 0.031 & 0.031 & 0.031 & 0.031 & 0.031 \\
\hline Obs & 27,879 & 27,879 & 27,879 & 27,879 & 27,879 \\
\hline
\end{tabular}


Table 7: [Continued]

\begin{tabular}{|c|c|c|c|}
\hline \multicolumn{4}{|c|}{ Panel B: Regression Results of Future Changes in ROA } \\
\hline Dependent Variable: & $\begin{array}{c}\text { FY2 ROA - } \\
\text { FY1 ROA }\end{array}$ & $\begin{array}{c}\text { FY3 ROA - } \\
\text { FY2 ROA }\end{array}$ & $\begin{array}{c}\text { FY3 ROA - } \\
\text { Current ROA } \\
\end{array}$ \\
\hline & (1) & (2) & (3) \\
\hline N-Score & $\begin{array}{c}0.003^{* *} \\
(2.95)\end{array}$ & $\begin{array}{l}0.002 \\
(1.55)\end{array}$ & $\begin{array}{c}0.011^{* * *} \\
(4.54)\end{array}$ \\
\hline $\mathrm{LAG}(\triangle \mathrm{ROA})$ & $\begin{array}{l}0.003 \\
(0.21)\end{array}$ & $\begin{array}{l}0.008 \\
(1.37)\end{array}$ & $\begin{array}{l}-0.052 \\
(-1.61)\end{array}$ \\
\hline MOMEN & $\begin{array}{l}-0.006 \\
(-1.28)\end{array}$ & $\begin{array}{c}-0.012 * * * \\
(-4.26)\end{array}$ & $\begin{array}{l}0.002 \\
(0.19)\end{array}$ \\
\hline LBM & $\begin{array}{l}-0.002 \\
(-0.45)\end{array}$ & $\begin{array}{l}-0.010 \\
(-1.29)\end{array}$ & $\begin{array}{l}0.004 \\
(0.19)\end{array}$ \\
\hline SIZE & $\begin{array}{l}-0.004 \\
(-1.05)\end{array}$ & $\begin{array}{l}-0.002 \\
(-1.16)\end{array}$ & $\begin{array}{l}-0.001 \\
(-0.18)\end{array}$ \\
\hline RND & $\begin{array}{c}0.001 * * * \\
(3.57)\end{array}$ & $\begin{array}{l}0.001 \\
(0.73)\end{array}$ & $\begin{array}{c}0.004 * * * \\
(5.23)\end{array}$ \\
\hline LVG & $\begin{array}{l}0.019 \\
(1.33)\end{array}$ & $\begin{array}{l}0.011 \\
(1.31)\end{array}$ & $\begin{array}{c}0.044 * * * \\
(2.84)\end{array}$ \\
\hline ASSETS & $\begin{array}{l}0.001 \\
(0.24)\end{array}$ & $\begin{array}{l}0.002 \\
(0.87)\end{array}$ & $\begin{array}{l}0.006 \\
(0.77)\end{array}$ \\
\hline SALES & $\begin{array}{l}0.001 \\
(1.00)\end{array}$ & $\begin{array}{l}-0.001 \\
(-0.58)\end{array}$ & $\begin{array}{l}-0.009 \\
(-1.22)\end{array}$ \\
\hline AGE & $\begin{array}{l}-0.000 \\
(-0.03)\end{array}$ & $\begin{array}{l}0.001 \\
(0.94)\end{array}$ & $\begin{array}{l}-0.010 \\
(-1.29)\end{array}$ \\
\hline Intercept & $\begin{array}{l}0.019 \\
(0.62) \\
\end{array}$ & $\begin{array}{l}0.014^{*} \\
(1.72) \\
\end{array}$ & $\begin{array}{l}0.049 \\
(1.46) \\
\end{array}$ \\
\hline R-square & 0.007 & 0.010 & 0.025 \\
\hline Obs & 22,703 & 18,077 & 18,077 \\
\hline
\end{tabular}


Table 8

Subsample Analysis of Changes in ROA

The table below contains results from regressing firm-specific one-year-ahead changes in ROA (i.e., FY1 ROA minus current ROA) minus the contemporaneous change in industry median ROA on quintiles of N-Score. N-Score equals the average quintile rank of the four centrality measures (DEGREE, CLOSENESS, BETWEENNESS, and EIGENVECTOR), rounded to the nearest integer. Quintile ranks are formed each June using the centrality measures from the most recent year, where higher (lower) values are assigned a rank of 5 (1). Each column in the table corresponds to the listed subsample. Growth, Young, Low ROA, and Low RET indicate that the analysis is conducted on subsamples where the firm is the lowest tercile of LBM, AGE, ROA, and MOMEN, respectively. The 'Coefficient Test' contains p-values from tests of the null hypothesis that the N-Score coefficient is different for the subsample relative to its sample counterpart. LBM is the $\log$ of 1 plus the firm's book-to-market ratio, AGE is the log of the number of prior months that the firm appears in CRSP, ROA is the firm's net income scaled by lagged assets, and MOMEN is the firm's marketadjusted returns over the 12 months prior to portfolio formation. SIZE equals the log of market capitalization, SALES is the log of total sales, and ASSETS is the log of total assets. LAG $(\triangle \mathrm{ROA})$ equals a firm's lagged change in ROA. Industry and year fixed-effects based on two-digit GICS codes are included throughout. The t-statistics based on two-way (firm and year) cluster robust standard errors are shown in parentheses. Levels of significance are indicated by *,**, and *** for $10 \%, 5 \%$, and $1 \%$, respectively.

\begin{tabular}{|c|c|c|c|c|c|c|c|}
\hline Sample: & All & Growth & Young & Low ROA & Low Ret & $\begin{array}{l}\text { Growth } \\
\text { \& Young }\end{array}$ & $\begin{array}{l}\text { Low ROA } \\
\& \text { Low Ret }\end{array}$ \\
\hline & $(1)$ & (2) & (3) & (4) & (5) & (6) & (7) \\
\hline N-Score & $\begin{array}{c}0.005^{* * *} \\
(3.00)\end{array}$ & $\begin{array}{c}0.009 * * * \\
(3.07)\end{array}$ & $\begin{array}{c}0.009^{* * *} \\
(2.76)\end{array}$ & $\begin{array}{l}0.003 \\
(1.19)\end{array}$ & $\begin{array}{c}0.007^{* * *} \\
(3.78)\end{array}$ & $\begin{array}{c}0.016^{* * *} \\
(3.48)\end{array}$ & $\begin{array}{l}0.003 \\
(1.08)\end{array}$ \\
\hline $\mathrm{LAG}(\Delta \mathrm{ROA})$ & $\begin{array}{c}-0.066^{*} \\
(-1.89)\end{array}$ & $\begin{array}{c}-0.097 * * * \\
(-3.26)\end{array}$ & $\begin{array}{c}-0.040^{* *} \\
(-2.18)\end{array}$ & $\begin{array}{c}-0.048^{* *} \\
(-2.39)\end{array}$ & $\begin{array}{c}-0.044^{*} \\
(-1.84)\end{array}$ & $\begin{array}{c}-0.081 * * * \\
(-3.99)\end{array}$ & $\begin{array}{c}-0.040 * * * \\
(-2.94)\end{array}$ \\
\hline MOMEN & $\begin{array}{c}0.028^{* * *} \\
(4.03)\end{array}$ & $\begin{array}{c}0.031^{* * *} \\
(3.53)\end{array}$ & $\begin{array}{c}0.028^{* *} \\
(2.50)\end{array}$ & $\begin{array}{c}0.019^{*} \\
(1.80)\end{array}$ & $\begin{array}{l}0.020 \\
(0.48)\end{array}$ & $\begin{array}{c}0.035^{* *} \\
(2.27)\end{array}$ & $\begin{array}{l}-0.027 \\
(-0.49)\end{array}$ \\
\hline LBM & $\begin{array}{l}-0.002 \\
(-0.08)\end{array}$ & $\begin{array}{c}-0.109 * * * \\
(-2.75)\end{array}$ & $\begin{array}{l}0.023 \\
(0.90)\end{array}$ & $\begin{array}{l}-0.023 \\
(-1.41)\end{array}$ & $\begin{array}{l}0.003 \\
(0.10)\end{array}$ & $\begin{array}{c}-0.088^{* *} \\
(-2.03)\end{array}$ & $\begin{array}{l}-0.016 \\
(-0.58)\end{array}$ \\
\hline SIZE & $\begin{array}{l}0.007 \\
(1.51)\end{array}$ & $\begin{array}{l}-0.001 \\
(-0.18)\end{array}$ & $\begin{array}{l}0.011 \\
(1.47)\end{array}$ & $\begin{array}{c}0.018^{* *} \\
(2.33)\end{array}$ & $\begin{array}{l}0.002 \\
(0.30)\end{array}$ & $\begin{array}{l}0.003 \\
(0.37)\end{array}$ & $\begin{array}{l}0.015 \\
(1.10)\end{array}$ \\
\hline RND & $\begin{array}{l}0.001 \\
(1.57)\end{array}$ & $\begin{array}{l}-0.000 \\
(-0.14)\end{array}$ & $\begin{array}{l}0.001 \\
(0.61)\end{array}$ & $\begin{array}{l}0.000 \\
(0.22)\end{array}$ & $\begin{array}{l}-0.000 \\
(-0.37)\end{array}$ & $\begin{array}{l}0.001 \\
(0.57)\end{array}$ & $\begin{array}{l}-0.001 \\
(-0.56)\end{array}$ \\
\hline LVG & $\begin{array}{c}0.020 * * * \\
(3.43)\end{array}$ & $\begin{array}{l}-0.001 \\
(-0.07)\end{array}$ & $\begin{array}{c}0.034 * * * \\
(3.22)\end{array}$ & $\begin{array}{l}-0.003 \\
(-0.16)\end{array}$ & $\begin{array}{l}0.024 \\
(1.47)\end{array}$ & $\begin{array}{c}0.026^{* *} \\
(2.17)\end{array}$ & $\begin{array}{l}-0.008 \\
(-0.32)\end{array}$ \\
\hline ASSETS & $\begin{array}{l}0.003 \\
(0.70)\end{array}$ & $\begin{array}{c}0.013^{*} \\
(1.87)\end{array}$ & $\begin{array}{l}0.009 \\
(0.88)\end{array}$ & $\begin{array}{l}-0.013 \\
(-1.30)\end{array}$ & $\begin{array}{c}0.022 * \\
(1.82)\end{array}$ & $\begin{array}{l}0.013 \\
(1.34)\end{array}$ & $\begin{array}{l}0.005 \\
(0.29)\end{array}$ \\
\hline SALES & $\begin{array}{l}-0.012 \\
(-1.37)\end{array}$ & $\begin{array}{l}-0.014 \\
(-1.36)\end{array}$ & $\begin{array}{l}-0.022 \\
(-1.34)\end{array}$ & $\begin{array}{l}-0.001 \\
(-0.09)\end{array}$ & $\begin{array}{l}-0.026 \\
(-1.50)\end{array}$ & $\begin{array}{l}-0.017 \\
(-1.15)\end{array}$ & $\begin{array}{l}-0.014 \\
(-0.62)\end{array}$ \\
\hline AGE & $\begin{array}{l}-0.006 \\
(-1.17)\end{array}$ & $\begin{array}{l}-0.008 \\
(-1.29)\end{array}$ & $\begin{array}{l}-0.027 \\
(-1.41)\end{array}$ & $\begin{array}{c}-0.022^{* *} \\
(-1.96)\end{array}$ & $\begin{array}{l}-0.013 \\
(-1.40)\end{array}$ & $\begin{array}{l}-0.034 * \\
(-1.67)\end{array}$ & $\begin{array}{c}-0.026^{*} \\
(-1.87)\end{array}$ \\
\hline Intercept & $\begin{array}{l}-0.018 \\
(-0.85) \\
\end{array}$ & $\begin{array}{l}0.068 \\
(1.15)\end{array}$ & $\begin{array}{l}-0.006 \\
(-0.19) \\
\end{array}$ & $\begin{array}{l}0.065 \\
(1.17)\end{array}$ & $\begin{array}{l}0.040 \\
(0.74)\end{array}$ & $\begin{array}{l}0.094 \\
(1.31)\end{array}$ & $\begin{array}{l}0.070 \\
(0.67)\end{array}$ \\
\hline Obs & 27,879 & 9,874 & 9,887 & 9,870 & 9,874 & 3,735 & 4,774 \\
\hline $\mathrm{R}$-square & 0.031 & 0.044 & 0.038 & 0.042 & 0.029 & 0.054 & 0.039 \\
\hline $\mathrm{H}_{0}$ : Coefficient Test & & 0.0000 & 0.0002 & 0.0251 & 0.0431 & 0.0000 & 0.9030 \\
\hline
\end{tabular}


Table 9

\section{Realized Consensus Forecast Errors}

Panels A and B reports results from regressions of analyst consensus forecast errors on firm characteristics. The dependent variable In Panel A (B) is analyst consensus forecast errors for one-year-ahead (two-year-ahead) earnings, defined as actual earnings per share minus the consensus forecast and scaled by total assets per share. Forecast errors are measured as of June $30^{\text {th }}$ for earnings and regressed on the quintile ranks of five measures of board centrality. Descriptions of DEGREE, CLOSENESS, BETWEENNESS, and EIGENVECTOR are detailed in Section 3.2. Quintile ranks are formed each June using the centrality measures from the most recent year, where firms with higher (lower) centrality are assigned a rank of 5 (1). N-Score equals the average quintile rank of the four centrality measures, rounded to the nearest integer. GROWTH, YOUNG, LOWROA, and LOWRET are dummy variables that equal one if the firm is the lowest tercile of BTM, AGE, ROA, and MOMEN, respectively, and zero otherwise. MOMEN equals the firm's cumulative return over the 12 months prior to the June portfolio formation, LBM equals the log of 1 plus the firm's book-to-market ratio, LOSS equals one if the firm experienced a loss in the prior fiscal year and zero otherwise, and AGE is log of the number of prior months that the firm appears in CRSP. COV is the log of analyst coverage. LOSS is a dummy variable that equals one when the firm experienced a loss in the most recent fiscal year and ACC is the firm's accruals scaled by total assets. Panel C focuses on N-Score as the primary centrality measure in predicting analyst one-year-ahead forecast errors across subsamples of firms. The 'Coefficient Test' contains p-values from tests of the null hypothesis that the N-Score coefficient is different for the subsample relative to its sample counterpart. Industry and year fixed-effects are included throughout. The t-statistics based on two-way (firm and year) cluster robust standard errors are shown in parentheses. Levels of significance are indicated by $*$, **, and *** for 10\%, 5\%, and 1\%, respectively.

\begin{tabular}{|c|c|c|c|c|c|}
\hline \multicolumn{6}{|c|}{ Panel A: Regression Results of One-year ahead Analyst Forecast Errors } \\
\hline \multirow{3}{*}{ Quintile(DEGREE) } & (1) & (2) & (3) & (4) & (5) \\
\hline & $0.094 *$ & - & - & - & - \\
\hline & $(1.71)$ & - & - & - & - \\
\hline \multirow[t]{2}{*}{ Quintile(CLOSENESS) } & - & $0.118^{* *}$ & - & - & - \\
\hline & - & $(2.40)$ & - & - & - \\
\hline \multirow[t]{2}{*}{ Quintile(BETWEENNESS) } & - & - & $0.117^{* *}$ & - & - \\
\hline & - & - & $(2.01)$ & - & - \\
\hline \multirow[t]{2}{*}{ Quintile(EIGENVECTOR) } & - & - & - & $0.127 * *$ & - \\
\hline & - & - & - & $(2.20)$ & - \\
\hline \multirow[t]{2}{*}{ N-Score } & - & - & - & - & $0.129 * *$ \\
\hline & - & - & - & - & $(2.23)$ \\
\hline \multirow[t]{2}{*}{$\mathrm{COV}$} & $0.934 * * *$ & $0.933^{* * *} *$ & $0.931 * * *$ & $0.934 * * *$ & $0.931 * * *$ \\
\hline & $(7.16)$ & $(7.24)$ & $(7.03)$ & $(7.24)$ & $(7.12)$ \\
\hline \multirow[t]{2}{*}{ MOMEN } & $1.115^{* * *}$ & $1.124 * * *$ & $1.117^{* * *}$ & $1.125^{* * *}$ & $1.124 * * *$ \\
\hline & $(3.71)$ & $(3.74)$ & $(3.77)$ & $(3.71)$ & $(3.74)$ \\
\hline \multirow[t]{2}{*}{ GROWTH } & $-0.594 * * *$ & $-0.591 * * *$ & $-0.587 * * *$ & $-0.590 * * *$ & $-0.589 * * *$ \\
\hline & $(-3.11)$ & $(-3.13)$ & $(-3.07)$ & $(-3.13)$ & $(-3.10)$ \\
\hline \multirow[t]{2}{*}{ LOSS } & $-2.236 * * *$ & $-2.242^{* * *}$ & $-2.237 * * *$ & $-2.241 * * *$ & $-2.248^{* * *}$ \\
\hline & $(-4.16)$ & $(-4.17)$ & $(-4.19)$ & $(-4.11)$ & $(-4.18)$ \\
\hline \multirow[t]{2}{*}{ YOUNG } & 0.099 & 0.096 & 0.102 & 0.097 & 0.100 \\
\hline & $(0.52)$ & $(0.50)$ & $(0.54)$ & $(0.51)$ & $(0.53)$ \\
\hline \multirow[t]{2}{*}{ ACC } & -1.731 & -1.731 & -1.729 & -1.725 & -1.731 \\
\hline & $(-0.97)$ & $(-0.97)$ & $(-0.97)$ & $(-0.97)$ & $(-0.97)$ \\
\hline \multirow[t]{2}{*}{ Intercept } & $-2.937 * * *$ & $-2.989 * * *$ & $-2.981 * * *$ & $-3.011 * * *$ & $-2.964 * * *$ \\
\hline & $(-6.49)$ & $(-6.56)$ & $(-6.98)$ & $(-6.73)$ & $(-6.61)$ \\
\hline $\mathrm{R}$-square & 0.038 & 0.038 & 0.038 & 0.038 & 0.038 \\
\hline Obs & 19,281 & 19,281 & 19,281 & 19,281 & 19,281 \\
\hline
\end{tabular}




\section{Table 9: [Continued]}

\begin{tabular}{lccccc}
\hline Panel B: Regression Results of Two-year ahead & \multicolumn{7}{l}{ Analyst Forecast Errors } & & \\
\hline \multirow{3}{*}{ Quintile(DEGREE) } & $(1)$ & $(2)$ & $(3)$ & $(4)$ & $(5)$ \\
\cline { 2 - 6 } Quintile(CLOSENESS) & $0.278^{* *}$ & - & - & - & - \\
& $(2.29)$ & - & - & - & - \\
Quintile(BETWEENNESS) & - & $0.304^{* *}$ & - & - & - \\
& - & $(2.36)$ & - & - & - \\
Quintile(EIGENVECTOR) & - & - & $0.259^{* * *}$ & - & - \\
& - & - & $(2.85)$ & - & - \\
N-Score & - & - & - & $0.319^{* *}$ & - \\
& - & - & - & $(2.35)$ & - \\
COV & - & - & - & - & $0.310^{* * *}$ \\
& - & - & - & - & $(2.63)$ \\
MOMEN & $1.802^{* * *}$ & $1.805^{* * *}$ & $1.805^{* * *}$ & $1.807 * * *$ & $1.799^{* * *}$ \\
& $(6.97)$ & $(6.90)$ & $(7.19)$ & $(6.93)$ & $(6.94)$ \\
GROWTH & -0.006 & 0.009 & -0.016 & 0.009 & 0.002 \\
& $(-0.01)$ & $(0.02)$ & $(-0.03)$ & $(0.02)$ & $(0.00)$ \\
LOSS & $-2.128^{* * *}$ & $-2.125^{* * *}$ & $-2.124^{* * *}$ & $-2.125^{* * *}$ & $-2.125^{* * *}$ \\
& $(-7.40)$ & $(-7.37)$ & $(-7.50)$ & $(-7.39)$ & $(-7.43)$ \\
YOUNG & $-4.360^{* * *}$ & $-4.354^{* * *}$ & $-4.324^{* * *}$ & $-4.348^{* * *}$ & $-4.360^{* * *}$ \\
& $(-4.16)$ & $(-4.18)$ & $(-4.10)$ & $(-4.18)$ & $(-4.16)$ \\
ACC & -0.425 & -0.433 & -0.417 & -0.429 & -0.422 \\
& $(-0.81)$ & $(-0.82)$ & $(-0.79)$ & $(-0.82)$ & $(-0.80)$ \\
Intercept & -2.699 & -2.699 & -2.687 & -2.682 & -2.698 \\
& $(-1.46)$ & $(-1.46)$ & $(-1.46)$ & $(-1.46)$ & $(-1.46)$ \\
& $-5.766^{* * *}$ & $-5.839^{* * *}$ & $-5.751^{* * *}$ & $-5.881^{* * *}$ & $-5.742^{2 * *}$ \\
R-square & $(-7.80)$ & $(-8.28)$ & $(-6.88)$ & $(-8.70)$ & $(-7.59)$ \\
\hline Obs & 0.036 & 0.036 & 0.036 & 0.036 & 0.036 \\
\hline
\end{tabular}


Table 9: [Continued]

\begin{tabular}{|c|c|c|c|c|c|c|c|}
\hline \multicolumn{8}{|c|}{ Panel C: Forecast Errors across Sample Partitions } \\
\hline Sample: & All & Growth & Young & Low ROA & Low Ret & $\begin{array}{l}\text { Growth \& } \\
\text { Young }\end{array}$ & $\begin{array}{l}\text { Low ROA } \\
\text { \& Low Ret }\end{array}$ \\
\hline & $(1)$ & $(2)$ & (3) & (4) & (5) & (6) & $(7)$ \\
\hline N-Score & $\begin{array}{c}0.127^{* *} \\
(2.23)\end{array}$ & $\begin{array}{c}0.259^{* * *} \\
(2.80)\end{array}$ & $\begin{array}{c}0.317 * * * \\
(2.67)\end{array}$ & $\begin{array}{c}0.569 * * * \\
(2.89)\end{array}$ & $\begin{array}{c}0.311^{* * *} \\
(2.93)\end{array}$ & $\begin{array}{c}0.590^{* * *} \\
(2.60)\end{array}$ & $\begin{array}{c}0.762^{* * *} \\
(3.22)\end{array}$ \\
\hline $\mathrm{COV}$ & $\begin{array}{c}0.916^{* * *} \\
(6.79)\end{array}$ & $\begin{array}{c}1.435^{* * *} \\
(7.38)\end{array}$ & $\begin{array}{c}1.332^{* * *} \\
(5.54)\end{array}$ & $\begin{array}{c}1.691 * * * \\
(8.05)\end{array}$ & $\begin{array}{c}1.269 * * * \\
(3.87)\end{array}$ & $\begin{array}{c}1.869 * * * \\
(3.86)\end{array}$ & $\begin{array}{c}2.059 * * * \\
(4.75)\end{array}$ \\
\hline MOMEN & $\begin{array}{c}1.052^{* * *} \\
(3.99)\end{array}$ & $\begin{array}{c}0.907^{* * *} \\
(3.59)\end{array}$ & $\begin{array}{c}1.064 * * * \\
(3.01)\end{array}$ & $\begin{array}{c}0.678^{* *} \\
(2.22)\end{array}$ & $\begin{array}{c}3.859^{* *} \\
(2.30)\end{array}$ & $\begin{array}{c}1.089 * * \\
(2.55)\end{array}$ & $\begin{array}{l}2.885 \\
(1.51)\end{array}$ \\
\hline GROWTH & $\begin{array}{c}-0.562^{* * *} \\
(-2.92)\end{array}$ & - & $\begin{array}{c}-0.747 * * * \\
(-2.82)\end{array}$ & $\begin{array}{c}-1.397 * * * \\
(-3.82)\end{array}$ & $\begin{array}{c}-0.966^{* *} \\
(-2.05)\end{array}$ & - & $\begin{array}{c}-1.422^{* *} \\
(-2.55)\end{array}$ \\
\hline LOSS & $\begin{array}{c}-2.253 * * * \\
(-4.15)\end{array}$ & $\begin{array}{c}-2.531 * * * \\
(-6.79)\end{array}$ & $\begin{array}{c}-2.583^{* * *} \\
(-4.18)\end{array}$ & $\begin{array}{c}-2.438^{* * *} \\
(-3.84)\end{array}$ & $\begin{array}{c}-1.754^{* * *} \\
(-3.18)\end{array}$ & $\begin{array}{c}-3.411 * * * \\
(-4.59)\end{array}$ & $\begin{array}{c}-2.363^{* * *} \\
(-4.47)\end{array}$ \\
\hline YOUNG & $\begin{array}{l}0.089 \\
(0.46)\end{array}$ & $\begin{array}{l}0.116 \\
(0.45)\end{array}$ & - & $\begin{array}{l}0.127 \\
(0.24)\end{array}$ & $\begin{array}{l}0.445 \\
(0.96)\end{array}$ & - & $\begin{array}{l}0.576 \\
(0.80)\end{array}$ \\
\hline ACC & $\begin{array}{l}-1.804 \\
(-1.00)\end{array}$ & $\begin{array}{c}-2.594^{*} \\
(-1.90)\end{array}$ & $\begin{array}{c}-3.936 * * \\
(-2.37)\end{array}$ & $\begin{array}{l}-2.308 \\
(-0.82)\end{array}$ & $\begin{array}{l}-2.264 \\
(-0.97)\end{array}$ & $\begin{array}{c}-5.323^{* *} \\
(-2.34)\end{array}$ & $\begin{array}{l}-2.211 \\
(-0.79)\end{array}$ \\
\hline Intercept & $\begin{array}{c}-3.299 * * * \\
(-13.41) \\
\end{array}$ & $\begin{array}{c}-4.963^{* * *} \\
(-9.16) \\
\end{array}$ & $\begin{array}{c}-3.947 * * * \\
(-7.07) \\
\end{array}$ & $\begin{array}{c}-5.586^{* * *} \\
(-5.03) \\
\end{array}$ & $\begin{array}{c}-4.258^{* * *} \\
(-4.59) \\
\end{array}$ & $\begin{array}{c}-5.088^{* * *} \\
(-4.11) \\
\end{array}$ & $\begin{array}{c}-6.080^{* * *} \\
(-2.64) \\
\end{array}$ \\
\hline Obs & 19,281 & 7,148 & 6,242 & 5,483 & 6,108 & 2,827 & 2,726 \\
\hline R-square & 0.059 & 0.057 & 0.067 & 0.060 & 0.068 & 0.070 & 0.081 \\
\hline $\mathrm{H}_{0}$ : Coefficient Test & & 0.0318 & 0.0058 & 0.0000 & 0.0076 & 0.0000 & 0.0000 \\
\hline
\end{tabular}


Table 10

Robustness Tests

Panels A, B, and C report robustness tests for Tables 6,8 , and 9B, respectively, focusing on N-Score as the primary network centrality measure of interest. Each column in the table corresponds to the listed subsample. Growth, Young, Low ROA, and Low RET indicate that the analysis is conducted on subsamples where the firm is the lowest tercile of LBM, AGE, ROA, and MOMEN, respectively. LBM equals one plus the firm's book-to-market ratio, AGE is the log of the number of prior months that the firm appears in CRSP, ROA is the firm's net income scaled by lagged assets, and MOMEN is the firm's market-adjusted returns over the 12 months following portfolio formation. The 'Coefficient Test' contains p-values from tests of the null hypothesis that the N-Score coefficient is different for the subsample relative to its sample counterpart. Each robustness test adds on to the specifications in Tables 6, 8, and 9(B), seven standard governance control variables: the presence of a staggered board, the presence of a poison pill, whether the firm has limits to calling special meetings, the percent of directors classified as independent, an indicator for when a firm's CEO also serves as the chairman of the board, an indicator for a firm having dual-class shares, and the governance index (GIndex) of Gompers, Ishii, and Metrick (2003). We replace missing values of the G-Index (and other governance metrics variables obtained from the IRRC, such as Staggered Board, Poison Pill, Limits to Special Meetings, and Dual Class Shares) with 0, and create a dummy variable (omitted for the ease of reporting) to indicate missing IRRC data. MOMEN equals the firm's cumulative return over the 12 months prior to the June portfolio formation, LBM equals the log of 1 plus the firm's book-to-market ratio, and SIZE equals the $\log$ of market capitalization. LOSS is a dummy variable that equals one when the firm experienced a loss in the most recent fiscal year, ACC is the firm's accruals scaled by total assets, and ASSETS is the log of total assets. LAG $\triangle$ ROA) equals a firm's lagged change in ROA. Industry and year fixed-effects are included throughout. The t-statistics based on two-way (firm and year) cluster robust standard errors. Levels of significance are indicated by *, **, and *** for 10\%, 5\%, and 1\%, respectively.

\begin{tabular}{|c|c|c|c|c|c|c|c|}
\hline \multicolumn{8}{|c|}{ Panel A: Return Predictability across Sample Partitions } \\
\hline \multirow[t]{2}{*}{ Sample: } & All & Growth & Young & $\begin{array}{l}\text { Low } \\
\text { ROA }\end{array}$ & Low Ret & $\begin{array}{l}\text { Growth } \\
\text { \& Young }\end{array}$ & $\begin{array}{c}\text { Low ROA \& } \\
\text { Low Ret }\end{array}$ \\
\hline & $(1)$ & $(2)$ & (3) & (4) & $(5)$ & $(6)$ & $(7)$ \\
\hline \multirow[t]{2}{*}{ N-Score } & $0.011 * * *$ & $0.019 * * *$ & $0.023^{* * *}$ & $0.035^{* * *}$ & $0.026 * * *$ & $0.034 * * *$ & $0.043 * * *$ \\
\hline & $(3.62)$ & $(5.39)$ & $(5.39)$ & $(6.41)$ & $(5.46)$ & $(4.41)$ & $(5.77)$ \\
\hline \multirow[t]{2}{*}{ Staggered Board } & 0.002 & -0.002 & $-0.042^{* * *}$ & -0.034 & 0.002 & $-0.079 * *$ & -0.023 \\
\hline & $(0.21)$ & $(-0.15)$ & $(-0.15)$ & $(-1.62)$ & $(0.14)$ & $(-2.48)$ & $(-0.74)$ \\
\hline \multirow[t]{2}{*}{ Poison Pill } & -0.009 & -0.000 & $0.010^{* * *}$ & $-0.048^{* * *}$ & $-0.031^{* *}$ & 0.001 & $-0.094 * * *$ \\
\hline & $(-1.39)$ & $(-0.03)$ & $(-0.03)$ & $(-2.93)$ & $(-2.26)$ & $(0.06)$ & $(-2.92)$ \\
\hline \multirow[t]{2}{*}{ Limits Special Meeting } & -0.007 & -0.006 & $0.022 * * *$ & 0.000 & -0.020 & 0.026 & 0.010 \\
\hline & $(-0.57)$ & $(-0.30)$ & $(-0.30)$ & $(0.02)$ & $(-1.21)$ & $(0.46)$ & $(0.42)$ \\
\hline \multirow[t]{2}{*}{$\%$ Ind Directors } & -0.050 & $-0.088^{* * *}$ & $0.093^{* * *}$ & 0.030 & -0.016 & -0.010 & 0.004 \\
\hline & $(-1.57)$ & $(-3.02)$ & $(-3.02)$ & $(0.47)$ & $(-0.29)$ & $(-0.09)$ & $(0.16)$ \\
\hline \multirow[t]{2}{*}{ CEO Chairman } & -0.010 & $-0.025^{* *}$ & $-0.031 * * *$ & $-0.049 *$ & -0.014 & $-0.049 *$ & -0.051 \\
\hline & $(-1.36)$ & $(-2.19)$ & $(-2.19)$ & $(-1.79)$ & $(-0.70)$ & $(-1.79)$ & $(-1.09)$ \\
\hline \multirow[t]{2}{*}{ Dual Class Shares } & -0.028 & -0.024 & $0.007 * * *$ & 0.006 & -0.029 & $-0.059 * *$ & 0.017 \\
\hline & $(-1.42)$ & $(-1.06)$ & $(-1.06)$ & $(0.15)$ & $(-0.56)$ & $(-2.13)$ & $(0.17)$ \\
\hline \multirow[t]{2}{*}{ GINDEX } & 0.002 & $0.007^{* *}$ & $0.005^{* * *}$ & 0.006 & 0.002 & $0.015^{* *}$ & 0.001 \\
\hline & $(1.01)$ & $(2.21)$ & $(2.21)$ & $(1.26)$ & $(0.33)$ & $(2.18)$ & $(0.12)$ \\
\hline \multirow[t]{2}{*}{ Intercept } & 0.041 & -0.050 & $-0.079 * * *$ & -0.019 & 0.082 & 0.104 & 0.229 \\
\hline & $(0.68)$ & $(-0.70)$ & $(-0.70)$ & $(-0.23)$ & $(1.10)$ & $(0.63)$ & $(1.28)$ \\
\hline Obs & 29,637 & 9,874 & 9,887 & 9,870 & 9,874 & 3,735 & 4,774 \\
\hline R-square & 0.006 & 0.008 & 0.008 & 0.011 & 0.010 & 0.016 & 0.014 \\
\hline $\mathrm{H}_{0}$ : Coefficient Test & & 0.0278 & 0.0014 & 0.0000 & 0.0000 & 0.0008 & 0.0000 \\
\hline
\end{tabular}




\section{Table 10: [Continued]}

\begin{tabular}{|c|c|c|c|c|c|c|c|}
\hline \multicolumn{8}{|c|}{ Panel B: Industry-Adjusted $\Delta \mathrm{ROA}$ across Sample Partitions } \\
\hline \multirow[t]{2}{*}{ Sample: } & All & Growth & Young & $\begin{array}{l}\text { Low } \\
\text { ROA }\end{array}$ & Low Ret & $\begin{array}{l}\text { Growth } \\
\& \text { Young }\end{array}$ & $\begin{array}{c}\text { Low ROA \& } \\
\text { Low Ret }\end{array}$ \\
\hline & $(1)$ & (2) & (3) & (4) & (5) & (6) & $(7)$ \\
\hline \multirow[t]{2}{*}{ N-Score } & $0.005^{* * *}$ & $0.009 * * *$ & $0.008^{* * *}$ & 0.003 & $0.007 * * *$ & $0.016^{* * *}$ & 0.004 \\
\hline & $(2.98)$ & $(3.05)$ & $(2.71)$ & $(1.29)$ & $(4.21)$ & $(3.52)$ & $(1.30)$ \\
\hline \multirow[t]{2}{*}{$\mathrm{LAG}(\Delta \mathrm{ROA})$} & $-0.066^{*}$ & $-0.098 * * *$ & $-0.040 * *$ & $-0.049 * *$ & $-0.044 *$ & $-0.081 * * *$ & $-0.041 * * *$ \\
\hline & $(-1.90)$ & $(-3.28)$ & $(-2.18)$ & $(-2.40)$ & $(-1.85)$ & $(-3.99)$ & $(-2.89)$ \\
\hline \multirow[t]{2}{*}{ MOMEN } & $0.028^{* * *}$ & $0.031^{* * *}$ & $0.028^{* *}$ & $0.018^{*}$ & 0.020 & $0.036^{* *}$ & -0.030 \\
\hline & $(3.99)$ & $(3.59)$ & $(2.48)$ & $(1.72)$ & $(0.48)$ & $(2.29)$ & $(-0.56)$ \\
\hline \multirow[t]{2}{*}{ LBM } & -0.001 & $-0.109 * * *$ & 0.023 & -0.022 & 0.003 & $-0.087 * *$ & -0.015 \\
\hline & $(-0.08)$ & $(-2.74)$ & $(0.92)$ & $(-1.28)$ & $(0.11)$ & $(-1.99)$ & $(-0.55)$ \\
\hline \multirow[t]{2}{*}{ SIZE } & 0.007 & -0.001 & 0.010 & $0.019 * *$ & 0.002 & 0.003 & 0.018 \\
\hline & $(1.43)$ & $(-0.25)$ & $(1.39)$ & $(2.48)$ & $(0.30)$ & $(0.29)$ & $(1.30)$ \\
\hline \multirow[t]{2}{*}{ RND } & 0.001 & -0.000 & 0.001 & 0.000 & -0.000 & 0.001 & -0.001 \\
\hline & (1.58) & $(-0.13)$ & $(0.60)$ & $(0.25)$ & $(-0.38)$ & $(0.53)$ & $(-0.56)$ \\
\hline \multirow[t]{2}{*}{ LVG } & $0.020 * * *$ & -0.003 & $0.034 * * *$ & -0.002 & 0.026 & $0.026^{*}$ & -0.004 \\
\hline & $(3.29)$ & $(-0.20)$ & $(3.01)$ & $(-0.12)$ & $(1.52)$ & $(1.87)$ & $(-0.16)$ \\
\hline \multirow[t]{2}{*}{ ASSETS } & 0.003 & $0.013^{*}$ & 0.009 & -0.013 & $0.022 *$ & 0.012 & 0.006 \\
\hline & $(0.65)$ & $(1.80)$ & $(0.82)$ & $(-1.22)$ & $(1.82)$ & $(1.25)$ & $(0.37)$ \\
\hline \multirow[t]{2}{*}{ SALES } & -0.012 & -0.015 & -0.022 & -0.001 & -0.026 & -0.018 & -0.014 \\
\hline & $(-1.37)$ & $(-1.36)$ & $(-1.33)$ & $(-0.06)$ & $(-1.50)$ & $(-1.13)$ & $(-0.60)$ \\
\hline \multirow[t]{2}{*}{ AGE } & -0.007 & -0.010 & -0.028 & $-0.021 *$ & -0.013 & -0.037 & $-0.023^{*}$ \\
\hline & $(-1.25)$ & $(-1.35)$ & $(-1.46)$ & $(-1.92)$ & $(-1.39)$ & $(-1.61)$ & $(-1.71)$ \\
\hline \multirow[t]{2}{*}{ Staggered Board } & -0.001 & -0.003 & 0.013 & 0.006 & 0.002 & 0.002 & 0.011 \\
\hline & $(-0.47)$ & $(-0.58)$ & $(1.30)$ & $(0.75)$ & $(0.35)$ & $(0.09)$ & $(0.78)$ \\
\hline \multirow[t]{2}{*}{ Poison Pill } & $-0.005^{* *}$ & -0.001 & -0.006 & -0.009 & $-0.011^{* *}$ & -0.006 & -0.016 \\
\hline & $(-2.30)$ & $(-0.31)$ & $(-0.92)$ & $(-1.54)$ & $(-1.98)$ & $(-0.56)$ & $(-1.46)$ \\
\hline \multirow[t]{2}{*}{ Limits Special Meeting } & -0.002 & -0.000 & $0.005^{*}$ & -0.006 & -0.006 & 0.013 & -0.012 \\
\hline & $(-0.62)$ & $(-0.03)$ & $(1.89)$ & $(-0.92)$ & $(-1.54)$ & $(1.18)$ & $(-1.34)$ \\
\hline \multirow[t]{2}{*}{$\%$ Ind Directors } & 0.012 & 0.020 & 0.022 & 0.045 & 0.020 & $0.048^{*}$ & 0.049 \\
\hline & $(1.01)$ & $(1.17)$ & $(0.78)$ & $(1.43)$ & $(0.82)$ & $(1.71)$ & $(1.01)$ \\
\hline \multirow[t]{2}{*}{ CEO Chairman } & -0.002 & $-0.011 * * *$ & $-0.012 * *$ & $-0.020^{*}$ & -0.005 & $-0.019 *$ & $-0.033 * *$ \\
\hline & $(-0.56)$ & $(-4.46)$ & $(-2.16)$ & $(-1.66)$ & $(-0.78)$ & $(-1.91)$ & $(-2.13)$ \\
\hline \multirow[t]{2}{*}{ Dual Class Shares } & -0.002 & -0.003 & 0.004 & -0.010 & $-0.009 *$ & 0.012 & -0.012 \\
\hline & $(-0.67)$ & $(-0.50)$ & $(0.59)$ & $(-1.02)$ & $(-1.75)$ & $(0.82)$ & $(-1.08)$ \\
\hline \multirow[t]{2}{*}{ GINDEX } & $0.001^{* * *}$ & $0.002^{* * *}$ & 0.000 & -0.000 & 0.001 & 0.001 & -0.002 \\
\hline & $(3.47)$ & $(2.80)$ & $(0.32)$ & $(-0.41)$ & $(1.47)$ & $(0.70)$ & $(-1.14)$ \\
\hline \multirow[t]{2}{*}{ Intercept } & -0.023 & 0.064 & -0.005 & 0.005 & 0.031 & 0.090 & 0.003 \\
\hline & $(-0.96)$ & $(1.17)$ & $(-0.12)$ & $(0.11)$ & $(0.63)$ & $(0.87)$ & $(0.03)$ \\
\hline Obs & 27,879 & 9,874 & 9,887 & 9,870 & 9,874 & 3,735 & 4,774 \\
\hline $\mathrm{R}$-square & 0.032 & 0.045 & 0.038 & 0.043 & 0.029 & 0.055 & 0.042 \\
\hline $\mathrm{H}_{0}$ : Coefficient Test & & 0.0000 & 0.0000 & 0.0175 & 0.0374 & 0.0000 & 0.5787 \\
\hline
\end{tabular}




\section{Table 10: [Continued]}

\begin{tabular}{|c|c|c|c|c|c|c|c|}
\hline \multicolumn{8}{|c|}{ Panel C: Forecast Errors across Sample Partitions } \\
\hline \multirow[t]{2}{*}{ Sample: } & All & Growth & Young & $\begin{array}{l}\text { Low } \\
\text { ROA }\end{array}$ & Low Ret & $\begin{array}{l}\text { Growth } \\
\text { \& Young }\end{array}$ & $\begin{array}{l}\text { Low ROA } \\
\text { \& Low Ret }\end{array}$ \\
\hline & $(1)$ & (2) & (3) & (4) & $(5)$ & (6) & $(7)$ \\
\hline \multirow[t]{2}{*}{ N-Score } & $0.116^{*}$ & $0.249 * *$ & $0.316^{* *}$ & $0.576^{* * *}$ & $0.335^{* * *}$ & $0.594 * *$ & $0.820 * * *$ \\
\hline & $(1.77)$ & $(2.47)$ & $(2.56)$ & $(2.77)$ & $(2.84)$ & $(2.58)$ & $(3.34)$ \\
\hline \multirow[t]{2}{*}{$\mathrm{COV}$} & $0.755^{* * *}$ & $1.333^{* * *}$ & $1.362^{* * *}$ & $1.507^{* * *}$ & $1.228^{* * *}$ & $1.942^{* * *}$ & $1.917^{* * *}$ \\
\hline & $(7.29)$ & $(6.07)$ & $(5.10)$ & $(6.72)$ & $(3.32)$ & $(3.77)$ & $(3.82)$ \\
\hline \multirow[t]{2}{*}{ MOMEN } & $1.063^{* * *}$ & $0.925^{* * *}$ & $1.065^{* * *}$ & $0.690^{* *}$ & $3.864^{* *}$ & $1.084^{* *}$ & 2.877 \\
\hline & $(4.11)$ & $(3.65)$ & $(3.00)$ & $(2.26)$ & $(2.29)$ & $(2.54)$ & $(1.53)$ \\
\hline \multirow[t]{2}{*}{ GROWTH } & $-0.527 * * *$ & - & $-0.747 * * *$ & $-1.337 * * *$ & $-0.954^{* *}$ & - & $-1.381 * *$ \\
\hline & $(-2.75)$ & - & $(-2.82)$ & $(-3.46)$ & $(-2.03)$ & - & $(-2.36)$ \\
\hline \multirow[t]{2}{*}{ LOSS } & $-2.202^{* * *}$ & $-2.517 * * *$ & $-2.620^{* * *}$ & $-2.405^{* * *}$ & $-1.764 * * *$ & $-3.527 * * *$ & $-2.259 * * *$ \\
\hline & $(-4.05)$ & $(-6.56)$ & $(-4.23)$ & $(-3.80)$ & $(-3.11)$ & $(-4.66)$ & $(-4.63)$ \\
\hline \multirow[t]{2}{*}{ YOUNG } & 0.226 & 0.230 & - & 0.269 & 0.476 & - & 0.711 \\
\hline & $(0.92)$ & $(0.73)$ & - & $(0.47)$ & $(0.85)$ & - & $(0.94)$ \\
\hline \multirow[t]{2}{*}{ ACC } & -1.781 & $-2.569^{*}$ & $-3.937 * *$ & -2.302 & -2.274 & $-5.380^{* *}$ & -2.181 \\
\hline & $(-0.97)$ & $(-1.88)$ & $(-2.35)$ & $(-0.81)$ & $(-0.96)$ & $(-2.34)$ & $(-0.76)$ \\
\hline \multirow[t]{2}{*}{ Staggered Board } & $0.186^{*}$ & 0.236 & 0.045 & $0.776^{*}$ & 0.193 & 0.139 & 1.019 \\
\hline & $(1.74)$ & $(1.33)$ & $(0.13)$ & $(1.83)$ & $(0.76)$ & $(0.25)$ & $(1.56)$ \\
\hline \multirow[t]{2}{*}{ Poison Pill } & -0.151 & -0.139 & -0.063 & -0.662 & -0.139 & -0.145 & -0.812 \\
\hline & $(-1.01)$ & $(-0.88)$ & $(-0.26)$ & $(-1.36)$ & $(-0.41)$ & $(-0.34)$ & $(-0.89)$ \\
\hline \multirow[t]{2}{*}{ Limits Special Meeting } & 0.005 & $-0.254^{*}$ & -0.081 & -0.300 & -0.062 & -0.179 & -0.688 \\
\hline & $(0.04)$ & $(-1.68)$ & $(-0.32)$ & $(-1.20)$ & $(-0.27)$ & $(-0.36)$ & $(-1.57)$ \\
\hline \multirow[t]{2}{*}{$\%$ Ind Directors } & -0.679 & 0.156 & -0.760 & -2.959 & $-2.300 * *$ & -0.248 & $-5.634 *$ \\
\hline & $(-1.05)$ & $(0.28)$ & $(-0.57)$ & $(-1.42)$ & $(-2.19)$ & $(-0.12)$ & $(-1.89)$ \\
\hline \multirow[t]{2}{*}{ CEO Chairman } & -0.016 & $-0.353 * *$ & -0.025 & -0.410 & -0.112 & -0.126 & -0.556 \\
\hline & $(-0.10)$ & $(-2.27)$ & $(-0.15)$ & $(-0.77)$ & $(-0.24)$ & $(-0.47)$ & $(-0.58)$ \\
\hline \multirow[t]{2}{*}{ Dual Class Shares } & 0.045 & 0.246 & $-0.973^{* * *}$ & -0.155 & -0.244 & -0.917 & $-0.841 * *$ \\
\hline & $(0.31)$ & $(1.05)$ & $(-2.81)$ & $(-0.39)$ & $(-0.95)$ & $(-1.51)$ & $(-2.32)$ \\
\hline \multirow[t]{2}{*}{ GINDEX } & $0.047^{* *}$ & $0.100^{* * *}$ & $0.077^{*}$ & 0.090 & 0.038 & 0.124 & 0.056 \\
\hline & $(2.03)$ & $(2.68)$ & $(1.86)$ & $(1.23)$ & $(1.00)$ & $(1.24)$ & $(0.47)$ \\
\hline \multirow[t]{2}{*}{ Intercept } & $-2.823^{* * *}$ & $-5.538 * * *$ & $-4.128^{* * *}$ & $-3.060 * *$ & $-2.697 * * *$ & $-6.423 * * *$ & -0.984 \\
\hline & $(-6.10)$ & $(-7.64)$ & $(-3.37)$ & $(-2.10)$ & $(-3.09)$ & $(-3.44)$ & $(-0.34)$ \\
\hline Obs & 19,281 & 7,148 & 6,242 & 5,483 & 6,108 & 2,827 & 2,726 \\
\hline $\mathrm{R}$-square & 0.041 & 0.040 & 0.050 & 0.043 & 0.048 & 0.055 & 0.058 \\
\hline $\mathrm{H}_{0}$ : Coefficient Test & & 0.0368 & 0.0036 & 0.0000 & 0.0021 & 0.0000 & 0.0000 \\
\hline
\end{tabular}


Table 11

Changes in Centrality and Future Returns

Panel A contains the results from regressing firm-specific one-year-ahead characteristic-adjusted returns (BHAR1Y) on the one-year change in quintile ranks of five measures of board centrality. Descriptions of DEGREE, CLOSENESS, BETWEENNESS, and EIGENVECTOR are detailed in Section 3.2. Quintile ranks are formed each June using the centrality measures from the most recent year, where firms with higher (lower) centrality are assigned a rank of 5 (1). Changes are defined as a firm's current quintile rank minus its rank in the prior year. N-Score equals the average quintile rank of the four centrality measures, rounded to the nearest integer. All change variables are winsorized at -2 and 2 . Industry and year fixed-effects are included throughout. The t-statistics based on two-way (firm and year) cluster robust standard errors are shown in parentheses. Panel B contains the results from identical regressions, where the sample is limited to firms whose board composition is identical across the current and prior year. Characteristic-adjusted returns are calculated as of July $1^{\text {st }}$ of each year as the difference between a firm's cumulative return and the value-weighted average portfolio of firms matched by size, book-to-market, and momentum, where both returns are measured over identical holding periods. Levels of significance are indicated by $* * *$, and $* * *$ for $10 \%, 5 \%$, and $1 \%$, respectively. Panel C contains additional return regressions, where the sample is limited to firms whose board composition is identical across the current and prior year and whose board members have identical first-degree links across the current and prior year. Panel D contains one-year-ahead characteristic-adjusted returns and sample counts across portfolios double sorted by N-Score and $\Delta \mathrm{N}$-Score.

\begin{tabular}{|c|c|c|c|c|c|}
\hline \multicolumn{6}{|c|}{ Panel A: Results of One-Year-Ahead Characteristic-Adjusted Returns [Full Sample] } \\
\hline \multirow{3}{*}{$\triangle \mathrm{DEGREE}$} & (1) & (2) & (3) & (4) & (5) \\
\hline & $0.020^{* * *}$ & - & - & - & - \\
\hline & $(9.92)$ & - & - & - & - \\
\hline \multirow{2}{*}{$\triangle$ CLOSENESS } & - & $0.018^{* * *}$ & - & - & - \\
\hline & - & $(5.67)$ & - & - & - \\
\hline \multirow[t]{2}{*}{$\triangle B E T W E E N N E S S$} & - & - & $0.012^{* * *}$ & - & - \\
\hline & - & - & $(3.17)$ & - & - \\
\hline \multirow[t]{2}{*}{$\triangle$ EIGENVECTOR } & - & - & - & $0.010^{* * *}$ & - \\
\hline & - & - & - & $(3.17)$ & - \\
\hline \multirow[t]{2}{*}{$\Delta \mathrm{N}$-Score } & - & - & - & - & $0.019 * * *$ \\
\hline & - & - & - & - & $(6.04)$ \\
\hline \multirow[t]{2}{*}{ Intercept } & 0.024 & 0.024 & 0.024 & 0.024 & 0.024 \\
\hline & $(0.60)$ & $(0.61)$ & $(0.61)$ & $(0.62)$ & $(0.60)$ \\
\hline R-square & 0.011 & 0.011 & 0.011 & 0.011 & 0.011 \\
\hline Obs & 23,683 & 23,683 & 23,683 & 23,683 & 23,683 \\
\hline
\end{tabular}

\begin{tabular}{|c|c|c|c|c|c|}
\hline \multicolumn{6}{|c|}{ Panel B: Return Regression Results for Unchanged Board Sample } \\
\hline \multirow{3}{*}{$\triangle \mathrm{DEGREE}$} & $(1)$ & (2) & (3) & (4) & (5) \\
\hline & 0.010 & - & - & - & - \\
\hline & $(1.60)$ & - & - & - & - \\
\hline \multirow{2}{*}{$\triangle$ CLOSENESS } & - & $0.005^{*}$ & - & - & - \\
\hline & - & $(1.65)$ & - & - & - \\
\hline \multirow[t]{2}{*}{$\triangle B E T W E E N N E S S$} & - & - & $0.012 * *$ & - & - \\
\hline & - & - & $(2.15)$ & - & - \\
\hline \multirow[t]{2}{*}{$\triangle$ EIGENVECTOR } & - & - & - & 0.001 & - \\
\hline & - & - & 一 & $(0.31)$ & - \\
\hline \multirow[t]{2}{*}{$\Delta \mathrm{N}$-Score } & - & - & - & - & $0.013^{* * *}$ \\
\hline & - & - & - & - & $(4.16)$ \\
\hline \multirow[t]{2}{*}{ Intercept } & 0.060 & 0.059 & 0.059 & 0.059 & 0.059 \\
\hline & $(1.46)$ & $(1.46)$ & $(1.45)$ & $(1.45)$ & $(1.47)$ \\
\hline R-square & 0.014 & 0.014 & 0.014 & 0.014 & 0.014 \\
\hline Obs & 7,534 & 7,534 & 7,534 & 7,534 & 7,534 \\
\hline
\end{tabular}


Table 11: [Continued]

\begin{tabular}{lcccc}
\hline \multicolumn{5}{l}{ Panel C: Return Regression Results for Unchanged Board and First-Degree Links Sample } \\
\hline \multirow{2}{*}{$\Delta$ CLOSENESS } & $(1)$ & $(2)$ & $(3)$ & $(4)$ \\
& 0.020 & - & - & - \\
BBETWEENNESS & $(0.92)$ & - & - & - \\
& - & $0.028^{*}$ & - & - \\
SEIGENVECTOR & - & $(1.78)$ & - & - \\
& - & - & 0.004 & - \\
NN-Score & - & - & $(0.19)$ & - \\
& - & - & - & 0.028 \\
Intercept & - & - & - & $(1.26)$ \\
& 0.061 & 0.059 & 0.060 & 0.060 \\
\hline R-square & $(0.85)$ & $(0.77)$ & $(0.83)$ & $(0.83)$ \\
\hline Obs & 0.013 & 0.014 & 0.013 & 0.014 \\
\hline
\end{tabular}

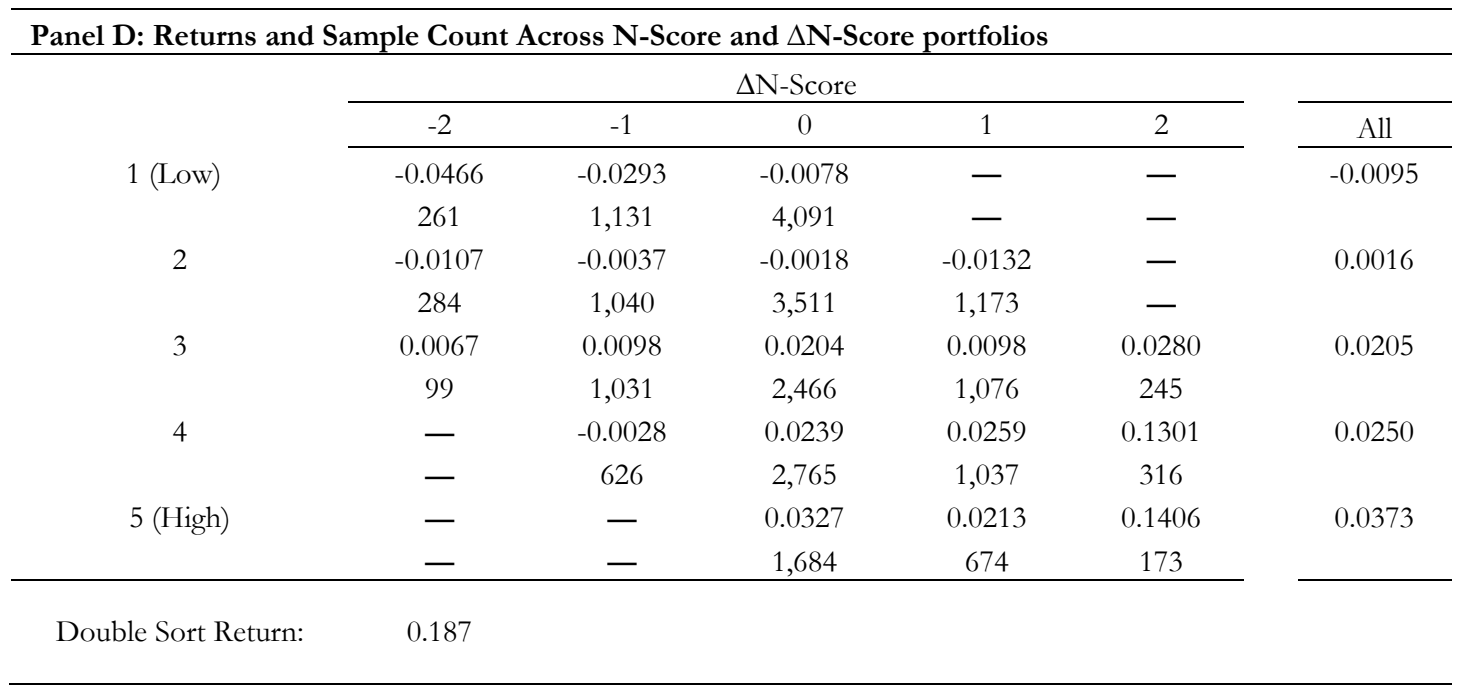

